\title{
Hacia un modelo europeo de control jurídico del poder ejecutivo
}

\author{
Fernando López Ramón
}

Catedrático de Derecho administrativo

Universidad de Zaragoza

SUMARIO: I. DIFERENGIAS Y GONFLUENGIAS EN LOS MODELOS DE GONTROL JURÍDICO DEL PODER EJEGUTIVO. II. LA REVISIÓN JUDICIAL BRITÁNICA. 1. Revisión judicial especializada. 2. Fundamentos. 3. Justicia cautelar. 4. Tribunales administrativos. III. LA JUSTICIA ADMINISTRATIVA FRANGESA. 1. La original justicia retenida. 2. La jurisdicción delegada. 3. Las transformaciones contemporáneas. 4. Las jurisdicciones especiales. IV. LA JURISDICGIÓN CONTENCIOSO-ADMINISTRATIVA ALEMANA. 1. La forja de la jurisdicción especializada. 2. Organización. 3. El requisito de la lesión jurídica de derechos individuales. 4. Acciones y justicia cautelar. V. EL CONTROL JURÍDICO DE LAS INSTITUCIONES DE LA UNIÓN EUROPEA. 1. El contencioso de la Unión. 2. Los tribunales especializados. 3. Las salas de recurso. 4. Eficacia del sistema. VI. RACIONALIZACIÓN, FLEXIBILIDAD, ESPECIALIZACIÓN Y GOLABORACIÓN EN EL MODELO EUROPEO DE GONTROL JURÍDICO DEL PODER EJEGUTIVO. BIBLIOGRAFÍA.

RESUMEN: Hacia un modelo europeo de control jurídico del poder ejecutivo. El primer objeto de este trabajo es poner de relieve las características propias de los tres grandes modelos europeos de control jurídico del poder ejecutivo: el judicial británico, el administrativo francés y el especializado alemán. A continuación, se consideran las posibilidades de configurar un modelo común europeo en la materia a partir de los polos de atracción que constituyen el derecho al proceso equitativo conforme a la jurisprudencia del Tribunal Europeo de Derechos Humanos, y especialmente la práctica del poliédrico y eficaz sistema de control jurídico establecido en la Unión Europea. A la vista de la evolución de los diferentes modelos históricos y teniendo en cuenta la particular atracción del practicado en la Unión Europea, se intenta diseñar algunas características de ese modelo común: racionalización, flexibilidad, especialización y colaboración. 
PALABRAS CLAVE: Control jurídico de la Administración, revisión judicial británica, justicia administrativa francesa, jurisdicción contencioso-administrativa alemana, derecho humano a la justicia, sistema judicial de la Unión Europea.

ABSTRACT. Towards an European model of juridical control of the executive power. The purpose of this paper is to expose the characteristics of the three main European models of legal control of administrative powers: the British judicial review, the French administrative justice and the German specialized jurisdiction. The paper discusses the potential to progressively set-up a 'European model' based on the poles of attraction of the right to justice in accordance with the jurisprudence of the European Court of Human Rights, and specially the practice of the system of judicial review of the European Union. In view of the evolution of the different historical models and having in it counts the particular attraction of the practised one in the European Union, there is necessary to design a common model characterized by the rationalization, flexibility, specialization and collaboration.

KEY WORDS: Legal control of administrative powers, British judicial review, French administrative justice, German specialized jurisdiction, right to justice, European judicial system.

\section{DIFERENGIAS Y CONFLUENGIAS EN LOS MODELOS DE CONTROL JURÍDICO DEL PODER EJEGUTIVO}

En Europa, se han alumbrado tres grandes modelos de control jurídico del poder ejecutivo: la revisión judicial británica llevada a cabo por los jueces ordinarios, la justicia administrativa francesa ejercida por los funcionarios del Consejo de Estado y la jurisdicción contencioso-administrativa alemana correspondiente a jueces especializados ${ }^{1}$.

Cada uno de esos modelos se vincula a distintas vicisitudes históricas, que permiten explicar los rasgos diferenciales en origen. El modelo británico parece proce-

1 Empleo la expresión control jurídico para referirme a los mecanismos institucionales que garantizan, mediante órganos independientes, la observancia del ordenamiento por parte de los poderes públicos encargados de funciones ejecutivas. Se pretende así utilizar una denominación neutral con respecto a los elementos personales que ejercen el indicado control jurídico, de manera que, en condiciones de real independencia, se comprenderían en el mismo tanto el control judicial genérico como el control administrativo o el control judicial especializado. Por otra parte, bajo la óptica del objeto y alcance del control me refiero, con la expresión control jurídico, al que cabría considerar de tipo general, al margen pues del control económico que corresponde a las jurisdicciones de cuentas. Finalmente, conviene también indicar que el control aquí considerado es el de tipo obligatorio, es decir, aquel que puede ser puesto en marcha por una parte legitimada sin contar con la voluntad de la otra parte; en consecuencia, los modos alternativos de resolución de conflictos (arbitraje, mediación, conciliación) no entran en nuestro análisis, dado que el empleo o la eficacia de los mismos depende de la voluntad confluente de las partes, que previamente han de pactar su aplicación. 
der, sin perjuicio de antecedentes más remotos, de la revolución liberal y puritana del siglo XVII, que contrapesó la implantación de la soberanía del parlamento con el respeto al Derecho de base igualitaria que habían ido creando los jueces territoriales. En cambio, el modelo francés surgió en la revolución burguesa del siglo XVIII, nutrida de fuertes dosis de desconfianza hacia los parlamentos judiciales del Antiguo Régimen, que determinaron la tajante separación de los poderes públicos y la subsiguiente creación del sistema de Derecho administrativo controlado por el Consejo de Estado. El modelo alemán, que no procede directamente de una gran revolución, combina, a través de la pluralidad de experiencias de distintos territorios en el siglo XIX, una tradición de cierto nivel de control del poder por los jueces ordinarios con la recepción del droit administratif y la conciencia sobre el especial carácter de los asuntos públicos.

Los tres modelos se han desarrollado siguiendo trayectorias propias, no siempre coherentes con los planteamientos conceptuales que se encontraban en sus respectivos orígenes. De esta manera, todavía en la actualidad cabría identificar problemas característicos de cada uno de los modelos de control jurídico del poder ejecutivo. El modelo británico se enfrenta a los tradicionales privilegios de la Corona, los poderes judiciales de las cámaras parlamentarias, las limitaciones en el control de los asuntos políticos o las facultades de los tribunales administrativos. El modelo francés plantea cuestiones relativas a la independencia del juez, la ejecución de sentencias, la saturación de asuntos, la exigencia del acto previo, el control de los actos políticos y de la discrecionalidad, además de las inherentes a la doble jurisdicción. El modelo alemán genera restricciones en materia de legitimación, control objetivo de legalidad de la actuación administrativa y revisión de los reglamentos. Por añadidura, cada uno de esos modelos ha ejercido influencia en otras experiencias europeas que han generado evoluciones propias ${ }^{2}$.

Esa variedad de sistemas, aun limitándonos al ámbito europeo, genera importantes problemas que terminan por incidir en la configuración del estatuto del ciudadano europeo. Desde la óptica de la construcción de las instituciones comunitarias, tempranamente J.M. Auby \& M. Fromont (1971: 2) aseguraban que "la economía

2 En el área vinculada a la revisión judicial británica, se sitúan los sistemas de control del ejecutivo de Dinamarca, Irlanda, Hungría, Chipre o Malta. En la línea de la justicia administrativa francesa figuran, en la actualidad, Bélgica, Holanda, Grecia o Italia. En el camino de la jurisdicción contencioso-administrativa alemana, cabe citar preliminarmente a los demás Estados de la Unión Europea: Finlandia, Suecia, España, Portugal, Luxemburgo, Polonia, Estonia, Letonia, Lituania, República Checa, Eslovaquia, Austria, Eslovenia, Rumanía, Bulgaria o Croacia. No obstante, un análisis más detenido revelaría distinciones significativas entre estas experiencias nacionales, tanto en los aspectos orgánicos (especialización, estructura en grados, y selección, formación y promoción de los jueces) como en los funcionales (legitimación, procedimiento, prueba, alcance de los poderes, en especial en materia de control de la discrecionalidad, y efectos de las decisiones). 
jurídica del Tratado de Roma supone la existencia en los Estados miembros de la Comunidad de instituciones jurídicas que permitan de una manera suficientemente eficaz la protección de los ciudadanos frente a los actos de la Administración", esto es, sistemas de reacción, "si no iguales, al menos de eficacia comparable". El transcurso del tiempo y la expansión del ámbito competencial y territorial de la Unión Europea confirman plenamente ese criterio.

Sin embargo, la construcción de un modelo europeo de control jurídico de la Administración no se presenta como una tarea directamente asumida por las instituciones europeas, sino más bien como el resultado de diferentes experiencias. En tal sentido, cabe identificar, al menos, dos vías de formación de ese modelo en los Estados europeos: la primera deriva de la común vinculación a las exigencias del derecho a la tutela judicial efectiva, particularmente conforme a la jurisprudencia supranacional del Tribunal Europeo de Derechos Humanos (TEDH) y la segunda se conecta al prestigio de las soluciones del propio sistema de control jurídico establecido en la Unión ${ }^{3}$.

La importancia de la jurisprudencia del TEDH podrá ser advertida al estudiar los tres grandes modelos de control jurídico del poder ejecutivo que nos proporcionan las experiencias nacionales. Constantemente se pone de relieve la incidencia esencial de los diversos contenidos del derecho al proceso equitativo garantizado principalmente por el Convenio Europeo de Derechos Humanos (CEDH: art. 6). Así, iremos viendo cómo muy diversas y esenciales garantías derivan del reconocimiento transnacional del citado derecho humano o de algunas de sus aplicaciones: la plenitud y profundidad de los poderes judiciales frente a la discrecionalidad administrativa en el caso británico, la imparcialidad e independencia de los órganos que ejercen el control en el caso francés, o la amplitud y efectividad de la legitimación para la alegación de todo tipo de violaciones del ordenamiento jurídico en el caso alemán. Podemos pues considerarlas garantías comunes al ámbito europeo, tal y como, por otra parte, se viene demostrando en diversos enfoques doctrinales ${ }^{4}$.

3 Si se me permite una simplificación evocadora del personal característico de cada una de esas dos líneas de evolución, cabría decir que los jueces de Estrasburgo aportan la garantía del derecho individual como base indispensable de cualquier modelo de control jurídico de la Administración, y los burócratas de Bruselas la radical exigencia de un eficaz sistema adherido al real funcionamiento de los mecanismos de control. De tal planteamiento no cabría, desde luego, deducir una suerte de atribución exclusiva a cada una de las instancias citadas de la correspondiente aportación, pues ambas, junto con otras influencias, contribuyen a la formación de ese modelo de control jurídico que probablemente ni siquiera habría de limitarse al ámbito europeo.

En el estudio y sistematización de la jurisprudencia del TEDH llevados a cabo por RODRÍGUEZ PONTÓN F.J. (2005), se advierte que el carácter equitativo del proceso establecido en el art. 6 del CEDH comprende tres bloques de exigencias, que cabe identificar como la independencia e imparcialidad de la justicia, la igualdad de armas en el proceso y la publicidad; el autor estudia también, en la jurispru- 
Es sin duda de suma relevancia advertir la importancia de esos enfoques dominados por el sistema de garantías establecido en el CEDH e impulsado por la jurisprudencia del TEDH. Sin embargo, aun considerando y asumiendo tal perspectiva, nosotros vamos a fijarnos preferentemente en los aspectos estructurales de la construcción de un modelo común. Para ello, tras exponer los sistemas nacionales básicos, consideraremos las pragmáticas soluciones ofrecidas en el control jurídico del poder ejecutivo de la propia Unión Europea ${ }^{5}$.

\section{LA REVISIÓN JUDICIAL BRITÁNICA}

\section{Revisión judicial especializada}

Pocas trayectorias constitucionales cuentan, entre los correspondientes estudiosos, con partidarios tan convencidos de la superioridad de su sistema como cabe encontrar en Inglaterra. De todos ellos, es probablemente A.V. Dicey (1915: 213) quien mayor influencia ha ejercido a través de su famosa comparación entre rule of law y droit administratif. El autor aseguraba que el Derecho administrativo había de considerarse contrario a las hipótesis fundamentales del ordenamiento inglés, al contrastar radicalmente con el característico dominio de la ley, que impone a las autoridades actuar con pleno sometimiento a las mismas reglas y a los mismos tribunales que los particulares. Sin embargo, el examen del modelo británico no deja de presentar,

dencia del tribunal de Estrasburgo, la aplicación de las garantías procesales al procedimiento administrativo debido al carácter sancionador de la decisión que se adopte en el mismo y en los supuestos de ausencia o limitaciones del control judicial ulterior, finalizando por propugnar una ponderada extensión de las reglas del proceso equitativo a los procedimientos administrativos. Con arreglo a una metodología empírica, PAULIAT, H., (2008: 225-233) llega a conclusiones muy similares, afirmando que "el proceso administrativo está sometido a obligaciones casi idénticas en los diferentes países, pese a las diferencias existentes según el modelo considerado" (ibídem: 225); aseveraciones de la autora que pueden considerarse apoyadas en el empírico coordinado por la misma sobre la base de una amplia encuesta dirigida a veinticinco jurisdicciones administrativas europeas, cuyos resultados se sistematizan en OBSERVATOIRE DES MUTATIONS INSTITUTIONNELLES ET JURIDIQUES DE L'UNIVERSITÉ DE LIMOGES (2007), ofreciendo "los rasgos comunes de un embrión de justicia administrativa europea" (ibídem: 18), que comprenden aspectos organizativos (especialización, estructura, profesionalización, estatuto de los jueces) y funcionales (legitimación, proceso y eficacia del control). Véanse también FROMONT, M., (2008) y GARCÍA DE ENTERRÍA, E. (2009).

Conviene notar que, a efectos de este trabajo, el resultado del referéndum británico contra la permanencia del Reino Unido en la Unión Europea (2016), si bien no facilita evidentemente la aproximación de las legislaciones nacionales, no supone que hayan de descartarse ni las comparaciones entre ordenamientos aquí propuestas ni el mismo influjo de las soluciones establecidas por el Derecho de la Unión. En todo caso, aun en la estricta óptica de la Unión Europea, no ha de olvidarse que el modelo británico es seguido por otros países cuya permanencia en la misma no está en discusión. 
junto a sus indudables aciertos, relevantes limitaciones y excepciones a la plenitud del control judicial de los entes públicos (public bodies $)^{6}$.

El principio de revisión judicial pretende asegurar que los entes públicos dotados de poderes de regulación o intervención emplean dichos poderes dentro de los límites conferidos por el Parlamento. Viene ejerciéndose habitualmente en formaciones de un solo juez por las secciones (una en Londres y cuatro regionales) de la Corte Administrativa (Administrative Court), que forma parte de la Queen's or King's Bench Division dentro de la Corte Superior (High Court), así como por las cortes de Condado (County Courts) en relación con decisiones de las autoridades locales ${ }^{7}$. Se da, en consecuencia, una especialización material dentro de la organización judicial, caracterización que comprende también el desarrollo y el alcance del proceso que ha de seguirse ante los órganos judiciales citados.

Se trata, así, de un estricto control de legalidad, mediante el cual los jueces garantizan que la actuación administrativa se ha desenvuelto conforme a las reglas específicas (estatutarias) y generales (Common Law) aplicables. El control tradicional se limitaba a los aspectos de competencia y procedimiento, entendiéndose que la revisión judicial no alcanzaba a los errores en la aplicación del Derecho, considerados como admisibles dentro de la esfera de poder libre de los entes públicos siempre que procedieran de la autoridad competente con arreglo a los principios de procedimiento de la llamada justicia natural. En la actualidad, la revisión judicial garantiza que las leyes son correctamente interpretadas, que la discrecionalidad se ejerce conforme a los parámetros jurídicos que la delimitan y que no hay violación de los derechos humanos, aunque siempre sin llegar a un control de oportunidad de la actuación administrativa. El resultado de la revisión judicial, cuando la actuación administrativa viole los anteriores límites, suele ser la anulación, pero no una nueva decisión administrativa, al menos, cuando exista algún margen para la decisión discrecional. Todo lo más, se obligará al ente público a actuar conforme a las reglas aplicables, de manera que no necesariamente la nueva decisión será más favorable para el interesado.

De cualquier manera, de la revisión judicial suelen excluirse las decisiones correspondientes a la prerrogativa regia, que comprende cuestiones políticas o de alta administración en ámbitos como las relaciones internacionales, la seguridad nacional, el otorgamiento de distinciones, las relaciones entre Gobierno y Parlamento o el nombramiento de ministros, al considerarse materias que dependen esencialmente

6 Para la exposición que sigue, se han empleado los conocidos manuales de WADE, W. \& FORSYTH, CH. (2014: parte VII) y BARNETT, H. (2015: cap. 24), así como, en castellano, HIMSWORTH, C.M.G. (1993).

Se traduce Court como Corte y Tribunal como Tribunal. 
del juicio político, por lo que su determinación corresponde al poder ejecutivo conforme al principio de división de poderes.

En las reformas procesales para Inglaterra y Gales de 1977-1981 se configuró un procedimiento de revisión judicial, luego modificado en 2000, que permite obtener no sólo las decisiones judiciales especiales (prerogative remedies) sino también las ordinarias, que antes solo cabía reclamar ante los órganos judiciales "ordinarios". Los remedios especiales de Derecho público son: quashing order (antes, certiorari) para anular con efectos retroactivos la decisión administrativa ilegal, prohibiting order (antes, prohibition) para prevenir el acto ilegal y mandatory order (antes, mandamus) para requerir una acción de la autoridad. Los remedios ordinarios de Derecho privado son: declaration para establecer la posición legal de las partes, injunction para suspender actuaciones injustas y damages para la indemnización de daños y perjuicios. Aunque en un principio parecía que el procedimiento especial no era exigible cuando se solicitaran las decisiones judiciales de Derecho privado, en el caso O'Reilly (1983), la Cámara de los Lores estableció que dicho procedimiento había de seguirse con exclusión de cualquier otro para todos los asuntos de Derecho público, sin perjuicio de determinadas excepciones, particularmente cuando los elementos jurídico-públicos resultaran colaterales en relación con los de Derecho privado. Entre los condicionantes del procedimiento especial de revisión judicial se encuentran el establecimiento de un plazo máximo de recurso (tres meses) y la exigencia de legitimación derivada de un interés suficiente en la materia, requisitos cuyo control se lleva a cabo, junto con otros aspectos, mediante la previa autorización judicial para recurrir.

En todo caso, conforme a la Common Law, el proceso se sujeta a dos relevantes reglas de "justicia natural": a) el juez debe ser independiente e imparcial y ser percibido como tal, de manera que no sólo ha de abstenerse por razón de sus intereses personales, sean patrimoniales o de otro tipo, sino siempre que, en aplicación de la doctrina de la "parcialidad aparente", "un observador equitativo e informado, habiendo considerado las circunstancias pertinentes, pudiera concluir que existe una posibilidad real de que el juez pueda ser parcial" (caso Porter, 2002); y b) nadie puede resultar afectado en un juicio sin la posibilidad de ser oído equitativamente, de manera que los procedimientos deben ser contradictorios, concediéndose un relevante papel a la audiencia pública de cuantos demuestren tener un interés suficiente en el asunto.

\section{Fundamentos}

Un resumen muy conocido de los fundamentos de la revisión judicial fue expuesto por lord Diplock en el caso GCHO (1985):

"Creo que la revisión judicial se ha desarrollado hasta un estado actual en el que, sin reproducir el análisis de los pasos por los que el desarrollo ha tenido 
lugar, se pueden clasificar en tres grupos las bases o parámetros a través de los que la acción administrativa puede ser sometida a control mediante la revisión judicial. Denominaría a la primera base "ilegalidad", a la segunda "irracionalidad" y a la tercera "impropiedad procesal". Eso no quiere decir que un ulterior desarrollo sobre una base casuística no pueda, en el curso del tiempo, añadir nuevos criterios. Me refiero en particular a la posible adopción en el futuro del principio de "proporcionalidad", ya conocido en el Derecho administrativo de varios Estados miembros de la CEE."

Conforme al fundamento de "ilegalidad", el ente público debe entender correctamente las normas que regulan su poder y aplicarlas consecuentemente. De esta manera, la revisión judicial comprende todos los vicios denominados ultra vires: errores de derecho, mala interpretación de los poderes legales, delegación irregular de poderes, actuación de mala fe o persiguiendo un fin no previsto en la norma, así como la decisión adoptada por consideraciones irrelevantes o ignorando elementos decisivos.

La base de "irracionalidad", de empleo más bien infrecuente, alcanza, según la divulgada expresión del caso Wednesbury (1948), a toda "decisión que desafía tan escandalosamente la lógica o los estándares morales aceptados que ninguna persona sensata que se hubiera ocupado de la cuestión habría llegado a tal decisión".

La "impropiedad procesal" o vicio de forma incluye todos los supuestos en los que la autoridad actúa ilícitamente, no por el contenido de la decisión adoptada, sino por el modo en el que desempeña sus funciones. A tal fin, cumplen un relevante papel los ya citados principios de la "justicia natural", que en la misma vía administrativa imponen la imparcialidad de la autoridad que toma la decisión y el respeto a los derechos de la audiencia justa (previa notificación de la acción administrativa, motivación suficiente de la misma y oportunidad adecuada de formular alegaciones). No obstante, de modo paulatino, se asiste a la formulación legislativa de las reglas de los diversos procedimientos administrativos, estableciéndose así estándares de conducta de las autoridades más fácilmente controlables en la revisión judicial.

Por fin, la aceptación del fundamento de la "proporcionalidad", que permitiría penetrar en la entraña del poder discrecional, encuentra fuertes obstáculos. Aunque cabe encontrar algunos casos en los que se ha aplicado la proporcionalidad como una consecuencia de la prohibición de irracionalidad establecida en el caso Wednesbury (1948), todavía en el caso Brind (1991) la Cámara de los Lores, dando primacía a la seguridad jurídica, rechazó decididamente su empleo por entender que la formación de los jueces era inadecuada para resolver un problema de acción administrativa. Sin embargo, por virtud de la Ley de Derechos Humanos de 1998, que supuso la plena incorporación del CEDH al ordenamiento británico, la doctrina de la pro- 
porcionalidad se considera aplicable, al menos en relación con las cláusulas relativas al contenido de tales derechos humanos, que exigen un examen atento (anxious scrutiny), persistiendo la polémica cuando la decisión administrativa no está directamente relacionada con tales derechos ${ }^{8}$. Un importante avance en esta materia se impuso por el TEDH en el caso Kingsley (2002) al considerar que la limitación de la revisión judicial a los aspectos procedimentales infringía el derecho al proceso equitativo reconocido en el art. 6 del CEDH.

\section{Justicia cautelar}

La cuestión de la tutela cautelar ha merecido poca importancia en la experiencia británica, sobre todo después de que las reformas de 1977-1981, al simplificar los procesos, los aceleraran notablemente, pasando a durar semanas o meses en vez de años. En todo caso, las normas sobre revisión judicial prevén los incidentes de suspensión de las decisiones públicas controvertidas, así como la adopción de cualquier otra medida cautelar que se estime necesaria en garantía de los derechos de defensa ${ }^{9}$.

Sin embargo, conforme a los planteamientos tradicionales de la Common Law, las anteriores reglas no parecían aplicables a la Corona ni a los ministros y departamentos que ejercen poderes en su nombre, al no sujetarse a las mismas normas procesales que se aplican a las autoridades administrativas. Posteriormente, en una característica pirueta del ordenamiento británico: a) la Ley de Procedimiento de la Corona (1947) cambió esa regla tradicional, asegurando la procedencia de acciones civiles o penales contra la Corona; b) no obstante, en diversos sectores, leyes posteriores han prohibido la imposición de decisiones judiciales contra la Corona excluyendo incluso toda suspensión; y c) finalmente, en la práctica, se aprecia que la Corona siempre observa puntualmente el contenido de las declaraciones judiciales.

El corazón del sistema británico fue puesto a prueba en el caso Factortame I (1990), donde se planteó la suspensión de una actuación del Parlamento ${ }^{10}$. El TJCE, al resolver una cuestión prejudicial planteada por la High Court, había resuelto que una disposición de la Ley de Marina Mercante de 1988 era contraria al Derecho comunitario y carecía de efectos. En consecuencia, la Corte británica ordenó no aplicar

\footnotetext{
En relación con el alcance del control judicial en las privatizaciones consistentes en la externalización de funciones públicas, véase CRAIG, P. (2012).

$9 \quad$ En los términos de la Ley de la Corte Suprema (1981) y la Resolución 53 (1977), cuando se admite la demanda de revisión judicial: a) si la medida que se pretende obtener es una orden de prohibición o de nulidad, el tribunal otorgará la tutela cautelar consistente en la suspensión del procedimiento relacionado con la solicitud hasta la adopción de la decisión final u otro momento anterior establecido judicialmente; y b) si se solicita cualquier otra medida, en todo momento el tribunal puede concederla, igual que en un proceso de Derecho privado.

10 Véase GARGÍA DE ENTERRÍA, E. (1998: 117-125).
} 
la ley en cuestión hasta tanto se resolviera el litigio principal. Sin embargo, la Court of Appeal anuló la anterior suspensión por estimarla inaceptable con arreglo a la Common Law y considerando que, si se trataba de una exigencia del Derecho Comunitario, debía plantearse formalmente como cuestión prejudicial ante la justicia comunitaria. A continuación, el TJCE declaró que "un tribunal nacional que, ante un caso relacionado con el Derecho comunitario, considere que el único obstáculo que le impide conceder tutela cautelar es una norma de Derecho nacional, debe inaplicar esa norma". Inmediatamente, la Cámara de los Lores adoptó la medida cautelar a favor de la compañía demandante.

\section{Tribunales administrativos}

Junto al sistema general de control judicial del poder ejecutivo, la experiencia británica se caracteriza también por la importancia de los tribunales administrativos especializados ${ }^{11}$. Inicialmente se trataba de órganos administrativos independientes cuya creación fueron autorizando leyes reguladoras de diversos sectores de actuación pública especialmente a lo largo del siglo $\mathrm{XX}^{12}$. Un primer intento de racionalizar los tribunales administrativos se llevó a cabo conforme a las directrices del Informe Franks (1957), que perseguía contener su proliferación y coordinar su régimen de organización y procedimiento, todo ello con la finalidad última de formar órganos justos, abiertos e imparciales. Más recientemente, el Informe Leggatt (2001), tras identificar más de setenta tribunales administrativos con reglas diferentes de composición, procedimiento y recursos, propuso iniciar un proceso de judicialización, que se puso en marcha con la creación en 2007 del Tribunal de Primer Grado (First-tier Tribunal) y el Tribunal Superior (Upper Tribunal). No obstante, la integración de los tribunales administrativos en este sistema judicializado no resulta ni mucho menos completa, pues continúan funcionando unos cincuenta tribunales administrativos (Administrative Tribunals) compuestos por juristas y otros especialistas, que atienden miles de demandas anuales en materias de inmigración, seguridad social, valoración del suelo, tributos, transportes, servicios sanitarios y sociales, educación, regulación económica y otras ${ }^{13}$.

11 Sobre el régimen de los tribunales administrativos en Reino Unido, véanse GARCÍA URETA, A. (2016), TORNOS MAS, J. (2016) y PANGALLOZZI, M.C. (2016)

12 Obsérvese que, en el sistema británico, al carecer los entes públicos de poderes de autotutela no suele exigirse el agotamiento jerárquico de la vía administrativa. De manera que sólo parece viable un recurso administrativo si está previsto en la ley con la finalidad de facilitar y garantizar la aplicación de la misma ley, lo que explica que se desarrolle ante órganos independientes de los que ejercen las tareas administrativas.

13 Para un estudio no ceñido a Reino Unido de la jurisprudencia del TEDH relativa a las condiciones de imparcialidad que, en determinadas circunstancias (como en caso de ejercicio de potestad sancionadora o cuando el control judicial posterior resulta limitado), deben observar los órganos que resuelven recursos administrativos, véase BARCELONA LLOP, J. (2016). 
Las resoluciones de los tribunales administrativos, tras agotar, en su caso, una instancia administrativa de recurso, generalmente pueden ser recurridas, según los casos, ante la Corte Superior (High Court) o la Sala Civil de la Corte de Apelación (Court of Appeal), de manera que se mantiene una garantía de cierta intervención judicial. Por su parte, las sentencias del Tribunal Superior (Upper Tribunal) y de la Sala Administrativa de la Corte Superior (High Court) admiten por lo común recurso ante la misma Sala Civil de la Corte de Apelación (Court of Appeal) y en casos de especial relevancia ante la Corte Suprema (Supreme Court), que desde 2009 ha asumido las tradicionales funciones judiciales anteriormente desempeñadas por la Cámara de los Lores. Se observará pues que la especialización administrativa deja de aplicarse en los órganos judiciales superiores, que generalmente limitan el alcance de su intervención a las cuestiones propiamente jurídicas o casacionales, sin intervenir en la fijación de los hechos del caso.

\section{LA JUSTICIA ADMINISTRATIVA FRANCESA}

\section{La original justicia retenida}

Como magistralmente puso de relieve A. DE Tocoueville (1858), la creación revolucionaria francesa del Derecho administrativo fue producto de una extraordinaria simbiosis entre el modelo inglés de la división de poderes y la continuidad de las técnicas absolutistas. El sistema de justicia administrativa se encuentra así dominado por el principio de separación entre el poder judicial y el ejecutivo establecido en 1790, que prohíbe a los jueces intervenir en los negocios administrativos (juger l'administration c'est encore administrer). ${ }^{14}$

14 La justicia administrativa francesa deriva de una formación histórica paradójica, consecuencia de lo que GARCÍA DE ENTERRÍA, E. (1994) denominó “visión heterodoxa” del principio de la división de poderes, entendiéndolo como principio de separación entre los poderes. En la Asamblea Nacional Constituyente, todavía en la fase revolucionaria inicial de la monarquía limitada (1789-1792) formalizada en la Constitución de 1791, se plantearon dos fórmulas para el control jurídico de la Administración: a) el establecimiento de un fuero jurisdiccional especial (proyecto Thouret, 1789); y b) el sistema de autocontrol al entenderse que el poder judicial no podía perturbar la actividad administrativa. Fue esta última la que triunfó en la aún vigente Ley de 16-24 agosto 1790, que prohíbe a los jueces intervenir en los negocios administrativos (art. 13: "Las funciones judiciales son diferentes y permanecerán siempre separadas de las funciones administrativas. Los jueces no podrán, so pena de prevaricación, perturbar de ninguna manera las actuaciones de los cuerpos administrativos, ni emplazar ante ellos a los administradores por razón de sus funciones"). Durante casi diez años, tanto bajo la Convención (1792-1794) como en el Directorio (17941799), esto es, a lo largo de la I República, la regla se reafirma, según cabe advertir en la Ley de 16 fructidor del año III (1795) (art. único: "Se prohíbe terminantemente a los tribunales conocer de los actos de administración, cualquiera que fuere su especie, bajo sanción”). Para la exposición que sigue, se han empleado los acreditados estudios de CHAPUS, R. (2008), DARCY \& M. PAILLET, G. (2000) y PACTEAU, B. (2005), así como, en castellano RAMBAUD, P. (1993), MODERNE, F. (1993), DE LA SIERRA, S. (2002), 
En los inicios, funcionó exclusivamente como sistema de ministro-juez ${ }^{15}$. Sin embargo, desde la reconstitución napoleónica del viejo Consejo Real en el Consejo de Estado (1799), la fuerte vinculación de esta institución al Gobierno permitió una prodigiosa consolidación y expansión de la misma particularmente en el ámbito contencioso $^{16}$. En el turbulento período de la llamada justicia retenida, el Consejo de Estado carecía de poderes de decisión de las controversias, habiendo de limitarse a elevar sus propuestas al Gobierno, además de circunscribir su intervención a una lista de asuntos por persistir la teoría del ministro-juez, que configuraba a éste como autoridad contenciosa de Derecho común ${ }^{17}$. Ahora bien, la posición del Consejo de

SANTAMARÍA DACAL, A.I. (2001) y LAFERRIÈRE, J. (2007). Además, la fundamental selección de jurisprudencia comentada de LONG, M., WEIL, P., BRAIBANT, G., DELVOLVÉ, P., \& GENEVOIS, B., (2013).

15 La prohibición de que los jueces entendieran de los asuntos administrativos se tradujo efectivamente en el sistema de Administración-juez o, más precisamente, de ministro-juez, pues era a los ministros a quienes como autoridades superiores correspondía resolver definitivamente los recursos administrativos. Las causas de tan peculiar régimen suelen encontrarse en: a) la continuidad y la inercia con respecto al sistema tradicional de Administración absolutista que implicaba la exención jurisdiccional para las operaciones administrativas, planteamiento que se deduce, como ya hemos indicado, del principio de separación de poderes, entendiendo que los jueces no pueden intervenir sobre los negocios administrativos, al contrario de lo que sucedía en Inglaterra, donde si ciertamente el ejecutivo no puede intervenir en los asuntos judiciales, los jueces en cambio sí pueden conocer de las decisiones de los agentes públicos, que no personifican nada que quepa situar por encima de los otros poderes; $b$ ) la oposición a los parlamentos judiciales, formados por el estamento nobiliario y que habían pretendido compartir poderes legislativos con el rey constituyendo así un gobierno de jueces que los revolucionarios quisieron evitar; y c) un conjunto variado de ideas y razones entre las que cabe referir la prevalencia de criterios opuestos al modelo de jurisdicciones especiales presentado como alternativa, la consideración de que los tribunales ordinarios eran ineptos en materia administrativa o el hallazgo de legitimidad para la justicia administrativa en el argumento de que la Administración democrática procede del pueblo. Y así, "por temor del juez-administrador, se adoptó el sistema del administrador-juez" (PACTEAU, B. 2005: 16).

16 El Consejo de Estado se creó en el art. 52 de la Constitución del año VIII (1799): "Bajo la dirección de los cónsules, un Consejo de Estado se encargará de redactar los proyectos de ley y los reglamentos administrativos $y$ de resolver las dificultades que se eleven en materia administrativa". Su filiación profunda habría de buscarse en el Consejo Real, cuyos antecedentes se remontan al siglo X y que si inicialmente era una institución asesora en materia de gobierno y administración, desde el siglo XVI desempeñaba también funciones jurisdiccionales, organizándose en varias secciones para el ejercicio de las distintas tareas.

17 El Consejo de Estado se va consolidando en un período de fuerte inestabilidad política, pues entre 1799 y 1870 se suceden variadas formas políticas en Francia: a) la dictadura de Napoleón (1799-1814), que se ejerce bajo la forma de Consulado en las Constituciones del año VIII (1799) y del año X (1802) y como I Imperio en la Constitución del año XII (1804); b) la etapa de la Restauración (1814-1830), cuando se adoptan los rasgos absolutistas del principio monárquico propugnado en el Congreso de Viena (1815) y que justificarán el cambio dinástico; c) la monarquía salida de la Revolución de Julio (1830-1848), que alumbra el orleanismo, sistema monárquico moderado que enseguida resultará insuficiente para las aspiraciones del proletariado; y d) el retorno de la dinastía napoleónica tras la Revolución de Febrero, primero bajo la efímera II República presidida por Luis Napoleón (1848-1851) y luego ya, tras el golpe de Estado del presidente convertido en Napoleón III, el II Imperio (1851-1870) regido por la Constitución de 1852, objeto de las reformas democratizadoras de 1860 que sostendrán el régimen hasta 1870. 
Estado a la cabeza de la jerarquía administrativa sirvió para dar autoridad suficiente a sus decisiones.

La primitiva distinción entre los asuntos gubernativos -concebidos como actividad discrecional, de mando, que no origina derechos subjetivos- y los asuntos contenciosos -manifestación de la actividad de gestión, donde surgen derechos de los administrados- entrañaba enormes limitaciones para el control de la legalidad de la actividad administrativa. En todo caso, esa diferenciación fue tenazmente compensada por el hallazgo, a partir de 1820, del recurso por exceso de poder, que permitió ir reduciendo el bloque de actos exentos de control a través de la sucesiva admisión de motivos de anulación: incompetencia, vicio de forma, desviación de poder, hasta comprender toda violación de la ley. Ese recurso objetivo, de anulación o de menor jurisdicción, se convirtió en protagonista del sistema frente al recurso ordinario, subjetivo o de plena jurisdicción, pues aunque el primero limitara sus efectos a la anulación del acto administrativo impugnado sin servir para el reconocimiento de derechos subjetivos, precisamente por ello, permitió la defensa de los intereses legítimos frente a la discrecionalidad administrativa ${ }^{18}$.

\section{La jurisdicción delegada}

Finalizado el II Imperio y proclamada la III República, el paso al ejercicio de la denominada jurisdicción delegada (1872), a pesar de implicar inmediatamente un cierto repliegue en la actividad del Consejo de Estado como puede identificarse en la consolidación de la doctrina del acto político, permitiría dar el golpe de gracia a la teoría del ministro-juez, conforme a las conclusiones del comisario del gobierno $\mathrm{M}$. Jagerschmidt en el caso Cadot (1889):

“...allí donde hay una autoridad con poder de decisión propio, pudiendo tomar decisiones administrativas ejecutorias, un debate contencioso puede nacer y el Consejo de Estado puede ser directamente requerido, basta

18 La afirmación del Consejo de Estado a lo largo del siglo XIX fue acompañada de graves controversias suscitadas por quienes lo consideraban contrario al principio de unidad jurisdiccional. Es conocida, por ejemplo, la postura del duque de Broglie (1828): "En derecho y en razón ¿puede haber algo llamado justicia administrativa? ¿no son expresiones malsonantes, heréticas o que, al menos, casan difícilmente juntas?". Los argumentos contra la dualidad jurisdiccional extendidos a lo largo del período se referían a la inexistencia ya de las razones que habían llevado a los primeros revolucionarios a desconfiar de los jueces y también a la defensa de la unidad jurisdiccional como garantía fundamental del justiciable, pues conlleva la desaparición de las complicaciones relativas a la jurisdicción competente o a la aplicación de la cosa juzgada entre los dos órdenes jurisdiccionales. Las razones a favor de la dualidad jurisdiccional versaban sobre el carácter altamente especializado del Derecho aplicable a la Administración y la escasa preparación para aplicarlo por parte de los jueces judiciales. Advertencia: con la redundante referencia a los jueces judiciales se trata de evitar confundirlos con los que cabría denominar jueces administrativos. 
para ello con que el debate haya nacido por efecto de una decisión de una autoridad administrativa sobre el litigio."

Ciertamente, el sistema resultó, así, indeclinablemente vinculado a la decisión administrativa previa y al robustecimiento de los privilegios administrativos, cuya formación se considera una consecuencia del principio de separación de la jurisdicción administrativa y la Administración activa ${ }^{19}$. Pero al propio tiempo, la justicia administrativa francesa fue expandiendo su ámbito real de actuación, llegando a originar un crónico estado de saturación de asuntos y retraso en la resolución de los mismos que, paradójicamente, constituye, a la vez, su mayor problema y el mejor testimonio de su éxito social.

Sucesivas modificaciones de la planta de la justicia administrativa han tratado de hacer frente al problema: a) en 1953, siguiendo la pauta de los consejos de prefectura, se crearon los tribunales administrativos, que constituyen la primera instancia de la justicia administrativa ${ }^{20}$; b) en 1987 hubieron de crearse las cortes administrativas de apelación, de ámbito interregional, a las que se transfirió la mayor parte de las competencias de apelación; y c) según el vigente Código de Justicia Administrativa (2000), el sistema sigue dominado por el Consejo de Estado, que ejerce principalmente competencias de casación, aunque también tiene atribuida la resolución directa de una serie de materias reservadas a su conocimiento exclusivo, además de cumplir con sus tradicionales tareas consultivas.

La consagración constitucional de la justicia administrativa fue afirmada por el Consejo Constitucional en dos conocidas decisiones de 22 julio 1980 y 23 enero $1987^{21}$. Conforme a esa doctrina, la garantía constitucional comprende la existencia de la justicia administrativa, su independencia con respecto al poder judicial y la afirmación de un ámbito de competencia exclusiva. Como uno de los principios fundamentales de las leyes de la República, se caracteriza la existencia de ese ámbito de

19 Véase la clásica monografia de CHEVALLIER, J. (1970), donde se demuestra la conexión entre la consagración jurisprudencial del principio (1872-1905) y la reducción de la eficacia de la censura jurisdiccional ejercida por el Consejo de Estado, al crecer los privilegios administrativos establecidos legalmente.

20 Ésta fue una reforma adoptada en la IV República (1946-1958) y mantenida en la V República (de 1958 hasta la actualidad), pese a la crisis sufrida por el Consejo de Estado en 1962-1963 a raíz de episodios relacionados con la guerra de Argelia. En el caso Canal, Robiny Godot (19 octubre 1962), el Consejo de Estado había anulado la ordenanza del presidente de la República por la que se instituía una Corte Militar de Justicia, al considerar que la misma desconocía abusivamente los principios generales del Derecho penal. Inmediatamente, el Consejo de Ministros presidido por el general De Gaulle denunció "que la intervención del Consejo de Estado salía del dominio del contencioso-administrativo" (24 octubre 1962), presentando un proyecto de reforma del Consejo de Estado cuyos amenazadores contenidos iniciales fueron diluyéndose hasta su aprobación por los Decretos de 30 julio 1963. Eso sí, la Corte de Justicia Militar fue restablecida por Ley de 15 enero 1963.

21 Véase DEL SAZ, S. (1992). 
competencia privilegiado para "la anulación o reforma de las decisiones adoptadas, en ejercicio de las prerrogativas del poder público, por las autoridades que ejercen el poder ejecutivo", principio que sólo admite excepciones en las materias reservadas por su naturaleza al poder judicial (estado de las personas, libertad individual y propiedad privada) y por virtud de decisiones legales adoptadas en nombre de "una buena administración de justicia”.

\section{Las transformaciones contemporáneas}

En realidad, la peculiaridad del sistema francés ya no se mantiene con el alcance que pudo tener en el pasado. En tal sentido, conviene tener en cuenta: a) que la incompetencia de los jueces judiciales en materia administrativa no es absoluta; b) que la separación estatutaria entre jueces judiciales y jueces administrativos no implica una falta de independencia de los segundos, que, si no formalmente, al menos sustantivamente pueden ser considerados como equivalentes a los integrantes del poder judicial; c) que la posible incidencia abusiva sobre los casos concretos de la dualidad de funciones -administrativas y judiciales- del Consejo de Estado, ha sido paliada por las exigencias del derecho al proceso equitativo, particularmente conforme a la jurisprudencia del TEDH; d) igualmente, que la apariencia de la figura del comisario del Gobierno ha sido moderada como consecuencia también de la jurisprudencia del mismo TEDH; y e) que las medidas cautelares hace tiempo que han dejado de configurarse limitativamente. Expongamos brevemente estos elementos a fin de comprender las transformaciones experimentadas.

En relación con el primer aspecto, cabe indicar que ya desde el período revolucionario una parte del contencioso-administrativo había venido siendo atribuido a la competencia judicial por vía legislativa en diversas materias, como expropiación, accidentes escolares, daños a vehículos públicos, servidumbres de utilidad pública, internamiento de enajenados o daños de origen terrorista. Desde 1872, la resolución de las cuestiones de competencia entre el poder judicial y la justicia administrativa corresponde al Tribunal de Conflictos, en cuya composición participan paritariamente consejeros de estado y magistrados de casación bajo la presidencia del ministro de Justicia, que sólo ocasionalmente interviene para resolver los empates, sin adoptar, por añadidura, una actitud de defensa sistemática de la competencia administrativa $^{22}$. Así, en la jurisprudencia de dicho Tribunal de Conflictos se ha establecido que

${ }_{22}$ Durante casi todo el período de la jurisdicción retenida, los conflictos se resolvían por el jefe del Estado (primer cónsul, emperador o rey) a propuesta del Consejo de Estado, sistema que resultaba abusivo al otorgar el control al Consejo de Estado encargado de ejercer la justicia administrativa. Durante la II República se constituyó el primer Tribunal de Conflictos de composición mixta, que tuvo una vida efímera (1849-1851). Al pasar a la jurisdicción delegada, la Ley de 24 mayo 1872 restableció el Tribunal de Conflictos organizado sobre la regla de la paridad (cuatro miembros del Consejo de Estado y otros cuatro de la 
el principio de separación ha de entenderse de manera relativa, considerando al juez judicial guardián natural de la propiedad privada y de la libertad individual, lo que ha llevado a reconocer la competencia judicial en relación con los servicios públicos de tipo industrial y comercial, la contratación privada de las Administraciones o la reacción frente a la vía de hecho ${ }^{23}$. En definitiva, la dualidad jurisdiccional se considera un elemento esencial de la concepción francesa del control de los poderes administrativos, pudiendo sostenerse que, junto al Derecho administrativo en sentido estricto controlado por el Consejo de Estado, el poder judicial ha generado un Derecho administrativo derivado.

Decíamos también, en segundo término, que la justicia administrativa francesa no puede ya considerarse ejercida por funcionarios de la Administración pública. Es cierto que el estatuto del personal al servicio de la justicia administrativa es distinto del aplicable al poder judicial, al integrarse el primero en los cuerpos de consejeros del Consejo de Estado, y de consejeros de los tribunales administrativos y las cortes administrativas de apelación. Sin embargo, las características de estos cuerpos de funcionarios los acercan al régimen propio del personal propiamente judicial: a) los sistemas de acceso están orientados a la selección de juristas bien preparados en las materias administrativas, de manera que el paso con alto grado de aprovechamiento por la elitista École Nationale d'Administration es la condición más habitual para el ingreso en los citados cuerpos de la justicia administrativa; b) la independencia real de los consejeros en el ejercicio de las funciones jurisdiccionales es una seña de identidad de la justicia administrativa que nadie parece poner en duda; y c) la inamovilidad de los consejeros de Estado es asimismo una característica practicada efectivamente, que ha sido ya legalmente establecida para los consejeros de los tribunales administrativos y las cortes administrativas de apelación.

Como tercer elemento a considerar, resaltábamos la posible incidencia abusiva sobre los casos concretos de la dualidad de funciones característica del Consejo de Estado, pues junto a las funciones jurisdiccionales la institución desarrolla también

Corte de Casación) bajo la presidencia del ministro de Justicia. La última reforma del Tribunal de Conflictos se produjo por la Ley de 28 enero 2015, que ha ampliado las modalidades de acceso a su jurisdicción.

23 En algunas materias el reparto de competencias entre las dos jurisdicciones resulta ciertamente complejo y abocado a la casuística. Así sucede, por ejemplo, en relación con el servicio público de la justicia, donde la dualidad jurisdiccional lleva a atribuir al juez administrativo las cuestiones organizativas (creación y supresión de tribunales judiciales, constitución del Consejo de la Magistratura, reclutamiento, carrera y sanciones de los jueces) y al juez judicial las de funcionamiento (actos de procedimiento, preparatorios, ejecución, policía judicial). En el caso Prefecto de la Guyana (1952), el Tribunal de Conflictos estimó que la acción indemnizatoria ejercida por varios oficiales ministeriales por la no provisión de las plazas de magistrado existentes en la Guyana se refería a la organización del servicio público de la justicia y no a su funcionamiento, por lo que recaía en el ámbito de competencias de la jurisdicción administrativa. 
funciones administrativas ${ }^{24}$. Conforme a los planteamientos tradicionales, la ambigüedad derivada del ejercicio de funciones no jurisdiccionales quedaba compensada por la riqueza de conocimientos y experiencia que el sistema proporcionaba a los consejeros, lo que terminaba reforzando el poder real, la autoridad del órgano y, en último extremo, la calidad de los servicios públicos afectados por sus intervenciones $^{25}$. De cualquier manera, la consideración del riesgo del juez prisionero de su anterior posición consultiva ha terminado por deteriorar la imagen de imparcialidad de la jurisdicción. Así, en el caso Procola (1995), el TEDH consideró violado el derecho al juez imparcial por haber participado, en el procedimiento administrativo de elaboración de un reglamento impugnado ante el Consejo de Estado de Luxemburgo, nada menos que cuatro de los cinco miembros que integraban su formación contenciosa; en tal situación, el recurrente podía "legítimamente temer que los miembros del comité del contencioso se sintieran ligados por el dictamen dado precedentemente"; "esta simple duda, tan poco justificada como pueda estar, basta para alterar la imagen del tribunal en cuestión" ${ }^{26}$. En la reforma aprobada por Decreto de 6 marzo 2008, se adoptaron medidas para separar las formaciones consultivas y contenciosas del Consejo de Estado.

En cuarto lugar, entre las variantes que han afectado al original sistema del Consejo de Estado francés, cabe referirse al comisario del Gobierno, actualmente denominado ponente público (rapporteur public). Figura controvertida, pues aunque es nombrado por decreto del Gobierno, su imparcialidad vendría garantizada por la

24 Entre las funciones administrativas del Consejo de Estado, cabe destacar las consistentes en informar los proyectos de ley y de ciertos decretos, que pueden tener carácter normativo genérico pero también incidir sobre situaciones individuales; asimismo realiza informes o estudios sobre cuestiones que considera problemáticas; incluso sus miembros desarrollan tareas de asesoramiento y otras misiones administrativas variadas compatibles con sus funciones dentro del Consejo de Estado.

25 En defensa del principio de la dualidad de funciones de la institución y la consiguiente doble afectación de sus miembros, se citaban incluso casos en los que el propio Consejo de Estado no había seguido el contenido de sus previos dictámenes aplicando el criterio de supremacía de la función jurisdiccional sobre la consultiva, aunque lo más frecuente era que el sentido de ambas funciones coincidiera en los casos concretos.

26 Sin embargo, ha de tenerse presente que no se ha condenado la dualidad de funciones de la institución, aunque deba vigilarse que no forme parte de la sección que enjuicia quien antes se ha expresado públicamente sobre el asunto. Como bien se pone de relieve en el siguiente texto del Comisario del Gobierno Bonichot (1996): "Difícil es defender la idea de que un tribunal puede, con la misma composición, dar sucesivamente un dictamen y un juicio sobre la misma cuestión, pero se puede hacer comprender a los jueces europeos, que por otra parte ya lo saben, que el Consejo de Estado es la expresión misma de la concepción francesa de la separación de poderes, que la dualidad de sus atribuciones le da un peso considerable frente al Estado y que este modo de funcionamiento, profundamente anclado en la concepción francesa, da resultados que en muchos países se busca alcanzar". Posteriormente, en los casos Kleyn (2003), Sacilor-Lormines (2006), UFC (2009) y Escoffier (2011), el TEDH ha precisado que no se opone a la dualidad de funciones de un mismo órgano, limitándose a considerar contrarios al principio de imparcialidad los supuestos en los que una persona se pronuncia sobre la misma cuestión sucesivamente en formaciones consultiva y contenciosa. 
extracción entre los miembros del órgano jurisdiccional correspondiente a propuesta del vicepresidente del Consejo de Estado o del Consejo Superior de los Tribunales Administrativos y las Cortes Administrativas de Apelación. Interviene en la fase de audiencia del contencioso-administrativo tras la presentación sucinta del objeto del proceso por parte del relator y la intervención de los abogados de las partes (recurrentes y Administración), exponiendo entonces sus conclusiones, donde explica el asunto y propone la manera de resolverlo. No es un representante de la Administración, pues presenta con independencia su criterio sobre los hechos y el derecho aplicable, aunque como miembro de la jurisdicción tiene obligación de aportar conclusiones claras, sin poder remitirse a la sabiduría del tribunal. Tradicionalmente participaba discretamente en la deliberación del asunto, pero tras los casos Kress (2001) y Martini (2006) del TEDH se limita a dar su criterio sin participar ni siquiera pasivamente en la deliberación, al considerarse tal participación incompatible con las apariencias de imparcialidad exigibles ${ }^{27}$.

Finalmente, la quinta cuestión aludida se refiere a la justicia cautelar, que ha experimentado una notable evolución en el Derecho francés. En la actualidad comprende: a) la práctica de pruebas cautelares sobre los hechos litigiosos (constat d'urgence); b) la adopción de todo tipo de medidas de conservación, instrucción e incluso medidas positivas de aplicación (référé administratif) ${ }^{28}$; y c) la tradicional suspensión de la ejecución del acto recurrido, que procede tanto en el supuesto de consecuencias difícilmente reparables como en el caso de actos manifiestamente ilegales (sursis à l'éxécution).

\section{Las jurisdicciones especiales}

Curiosamente, al igual que sucede en el caso británico, la justicia administrativa francesa no estaría adecuadamente presentada sin llamar la atención sobre la proliferación de jurisdicciones administrativas especiales. Hay unas treinta en la actualidad, cuya misma existencia pudiera suscitar dudas conforme a las exigencias de una buena administración de justicia pues complican el reparto de competencias y aumentan el riesgo de errores en los recurrentes, debiendo, además, tenerse en

27 Véase el comentario de la sentencia del caso Kress de SANTAMARÍA DACAL, A.I. (2002). Las reformas que sucesivamente han afecto al nuevo ponente público se han aprobado por Decretos de 7 enero 2009, 23 enero 2011 y 19 diciembre 2015.

${ }_{28} \quad$ El vigente régimen del référé permite emplearlo ordinariamente para medidas de constatación, instrucción o provisión, y con carácter de urgencia para medidas de suspensión, mantenimiento de la libertad y conservación. 
cuenta que la composición de muchas de estas jurisdicciones no parece garantizar la imparcialidad propia de los órganos de la justicia ${ }^{29}$.

La clasificación de estas jurisdicciones resulta compleja, pudiendo identificarse supuestos de estructura en dos grados, junto a otros que carecen de elementos coordinadores, y también casos aislados y únicos en su género ${ }^{30}$. Varían considerablemente el volumen de asuntos atendidos por cada jurisdicción y aun la naturaleza de sus funciones, que pueden comprender la resolución de recursos contra ciertas decisiones administrativas, la imposición de sanciones disciplinarias o la adopción de formas jurisdiccionales para la acción administrativa ${ }^{31}$. En su composición cabe emplear a magistrados profesionales, que a veces constituyen la mayoría del órgano, pero también se encuentran representantes de los interesados en sentido amplio, que pueden llegar a ser los componentes exclusivos del órgano en cuestión. En todo caso, cuando no está previsto otro recurso ante la justicia administrativa ordinaria, el Consejo de Estado admite recurso de casación contra las decisiones de estas jurisdicciones administrativas especiales.

La identificación del carácter jurisdiccional de un determinado organismo plantea problemas debido a que las correspondientes normas reguladoras a veces son equívocas o silencian toda referencia a la cuestión. La regularidad jurídica en la creación de jurisdicciones especiales exigiría que se aprobaran por ley, que estuvieran sustraídas del poder jerárquico a fin de poder actuar con independencia, que siguieran procedimientos contradictorios respetando los derechos de defensa, que motivaran adecuadamente sus decisiones y que éstas tuvieran efecto de cosa juzgada. El Consejo de Estado resume en dos condiciones el reconocimiento de la cualidad jurisdiccional: a) la condición formal consistente en que el organismo tenga poder

$29 \quad$ En el siglo XIX la lista de jurisdicciones especiales se agotaba enseguida, pues comprendía la Corte de Cuentas, la jurisdicción universitaria, las comisiones departamentales y los consejos de revisión en materia de presas. A lo largo del siglo XX, especialmente tras la Segunda Guerra Mundial, el número se multiplicó y todavía quedan unas cuantas, pese a que bastantes han desaparecido por causas variadas como haber cumplido la tarea encomendada en relación con operaciones bélicas o haber sido transformadas en órganos judiciales (en materias de accidentes de trabajo, evaluación de los bienes perdidos por los repatriados de Ultramar o comisionarios de la Bolsa de París).

30 Hay jurisdicciones especiales de un solo grado, no coordinadas por una instancia superior pese a ejercerse por una pluralidad de órganos, como sucede en el caso de las comisiones departamentales de trabajadores minusválidos. Otras cuentan con dos grados de jurisdicción, según cabe advertir en relación con los contenciosos de la ayuda social (comisiones departamentales y en apelación Comisión Central), de la profesión médica (consejos regionales y en apelación Consejo Nacional) y de la ordenación universitaria (consejos de administración y en apelación Consejo Superior). Y hay también jurisdicciones aisladas y únicas en su género, cual la Corte de Cuentas, el Consejo Superior de la Magistratura o la Comisión Bancaria.

31 Generalmente las jurisdicciones administrativas especiales acumulan su misión jurisdiccional con atribuciones de otro orden, como la emisión de informes o la adopción de resoluciones que pueden ser objeto de recurso ante la jurisdicción ordinaria. 
de decisión, de manera que si únicamente realiza funciones de informe o propuesta no puede ser una jurisdicción; y b) la condición material relativa a la resolución de conflictos relativos a la aplicación del Derecho administrativo ${ }^{32}$.

\section{LA JURISDICGIÓN CONTENCIOSO-ADMINISTRATIVA ALEMANA}

\section{La forja de la jurisdicción especializada}

Para el gran publicista O. Mayer (1903), el alcance de la garantía jurídica del particular en el Estado Absoluto se limitaba a los supuestos comprendidos en la teoría del fisco, que permitía indemnizar por los daños de las decisiones del príncipe, pero sin que éstas pudieran ser anuladas. Con tal planteamiento, cabía acentuar el significado de la revolución liberal en la materia, al igual que sucedió en el caso francé ${ }^{33}$. Sin embargo, entre los autores alemanes más recientes, parece prevalecer la idea de que el insigne publicista y otros autores de la doctrina clásica, en su intento de construir un Derecho administrativo de base francesa, pudieron extrapolar hacia el pasado la distinción entre asuntos civiles y administrativos tal y como se entendía en el siglo XIX. Suele así considerarse que en el Antiguo Régimen el particular tenía acceso pleno a la justicia, incluso frente al príncipe, en todos los "asuntos justiciables", habiéndose alcanzado una "situación próxima a un Estado de Derecho"34.

32 En todo caso ha de remitirse a la jurisprudencia en la materia del TEDH recientemente analizada por el ya citado BARCELONA, J., (2016).

33 Siguiendo la exposición de GONZÁLEZ-VARAS, S. (1993: 31-38), la doctrina clásica del Derecho público alemán (MAYER, O., FLEINER, JELLINEK, FORSTHOFF, WOLF) explicaba el surgimiento histórico de la teoría del fisco como un efecto de la decadencia del Imperio frente a los Estados (Prusia, Austria, Baviera...) tras la Guerra de los Treinta Años (1648). En el Derecho de las curias regias, especialmente a lo largo del siglo XVIII bajo el dominio del Despotismo Ilustrado, se contraponían: a) los asuntos de policía, identificados con la actividad general del monarca y su administración, que se regía por las leyes de policía, de las que el príncipe podía apartarse conforme a la razón de Estado; y b) los asuntos de justicia sujetos al Derecho civil bajo el control de los tribunales, a los que había de someterse el mismo príncipe. Pues bien, al decaer la jurisdicción imperial que controlaba la actividad de los príncipes territoriales, la teoría del fisco sirvió, particularmente a lo largo del siglo XIX, para corregir el detrimento de la garantía jurídica que conllevaba la anterior distinción, convirtiendo determinados asuntos de la policía administrativa en cosas de justicia sometidas a los tribunales civiles. Se reconciliaba así la nueva idea del Estado (Absoluto) con la omnipotencia del Derecho civil, cuyas garantías afectaban a las mismas prerrogativas regias, al menos en su significado económico, pues al Fisco, como persona jurídica de Derecho privado, se imputaba la responsabilidad por los daños que produjeran las decisiones del príncipe.

34 De nuevo conforme a la exposición del citado GONZÁLEZ-VARAS, S., (1993: 38-51), en la doctrina alemana (BULLINGER, RÜFFNER, ERICHSEN) prevalece ya el criterio de que, en el Antiguo Régimen, los asuntos justiciables permitían siempre el acceso a la justicia, sin que existan razones para sostener que los asuntos de policía estaban privados de protección jurídica, puesto que no se aplicaban los conceptos modernos de Derecho civil y Derecho público. Consideran así estos autores que los asuntos 
Esta nueva visión permitiría contemplar la jurisdicción contencioso-administrativa alemana actual como una vía de progreso histórico en la misma línea, que avanza en la noción tradicional de las cosas justiciables y el pleno carácter judicial del control del poder ejecutivo ${ }^{35}$.

Vemos pues que en el ámbito alemán no se produjo la violenta ruptura con la historia que tuvo lugar en la experiencia francesa ${ }^{36}$. Por ello quizá el sistema de justicia administrativa vinculado al Consejo de Estado no resultó convincente en Alemania, apreciándose a lo largo del siglo XIX posturas favorables a la aplicación de la corriente "judicialista" pura a los asuntos administrativos. Paulatinamente el concepto de cosa justiciable fue restringiéndose, hasta llegar un momento en el que los tribunales civiles sólo incluían en el mismo los asuntos de Derecho civil, produciendo el efecto de liberar al ejecutivo en buena medida del control judicial. De ahí los enfrentamientos entre los tradicionales seguidores de la justicia judicial y los nuevos partidarios de la justicia administrativa, que condujeron a variadas soluciones en los países germánicos.

Las primeras previsiones apuntaron al modelo francés, como cabe observar en el ejemplo del Consejo Secreto con una instancia de recurso previsto en la Constitución de Württenberg (1819: art. 60). Sin embargo, en el frustrado proyecto de Constitución del Estado Alemán aprobado, tras la revolución liberal, por la Asamblea Nacional reunida en la Paulkirche de Frankfurt (1849: art. 182) se establecía:

"Queda abolida la justicia ejercida por la Administración. Sobre cualquier lesión jurídica deciden los tribunales."

En esa misma línea, el paso fundamental correspondería a la Ley de Baden que estableció la jurisdicción contencioso-administrativa en 1863, aunque sólo en la instancia suprema se contaba con un tribunal integrado exclusivamente por jue-

justiciables comprendían cuestiones que hoy calificaríamos como administrativas, de la misma manera que la justicia se impartía por los tribunales y por órganos administrativos. Su conclusión es que, en el Estado Absoluto, el particular podía exigir frente al príncipe, por los cauces ordinarios, tanto la indemnización por los daños que su actividad le hubiera podido causar, como la anulación de sus decisiones antijurídicas.

35 Para la exposición que sigue, se ha empleado la siguiente literatura: los autores alemanes traducidos al español SOMMERMANN, K.P., (1993), SCHMIDT-ASSMANN, E., (2003: 225-250) y UHLE \& M. LEHR, A. (2007); y en la doctrina española, NIETO, A. (1960), BARNÉS VÁZQUEZ, J. (1993), GONZÁLEZ-VARAS, S., (1993) y HUERGO LORA, A., (2000: 33-147).

36 El siglo XIX en Alemania aparece marcado por la derrota del Imperio de Prusia (I Reich) por Napoleón (1806). Varios sustitutivos se intentaron sin éxito: la Federación del Rin constituida bajo los auspicios napoleónicos en 1806; la Confederación Germánica presidida por el emperador de Austria, que tutelaba los 39 Estados en los que se dividió Alemania en el Congreso de Viena (1815); la Unión Aduanera (1833); y el proyecto de Constitución paulista (1849). Finalmente, el II Reich, integrado por 25 Estados, se constituyó en 1871 por Guillermo II y Bismarck. 
ces independientes y profesionales, pues en las instancias inferiores se combinaba la presencia de jueces con la de funcionarios y se desempeñaban tanto funciones judiciales como administrativas. No obstante, para aminorar la influencia del factor burocrático y acercar al pueblo la justicia sobre el poder ejecutivo, en los tribunales contencioso-administrativos se preveían representantes populares, conformando una experiencia que todavía sigue vigente. En todo caso, el modelo de Baden se generalizó adoptándose por Prusia (1872), Hessen (1874), Württenberg (1874) y Baviera (1878), entre otros territorios.

Estos tribunales especializados en los litigios administrativos sirvieron para robustecer el gran Derecho público alemán, que aportó ideas muy claras sobre el principio de legalidad y sus exigencias en la jerarquía de las fuentes o en el control de la discrecionalidad. Entre los autores más influyentes, puede destacarse la importancia en esta materia de R. vON GNEIST (1872), que propugnaba el modelo prusiano de la jurisdicción contencioso-administrativa independiente aunque especializada, al aunar las ventajas de la justicia administrativa de estirpe francesa con el tradicional sistema de control judicial del ejecutivo.

En el siglo XX terminó por forjarse la opción característica del ordenamiento alemán de atribuir el ejercicio de las funciones de control de la Administración a tribunales especializados ${ }^{37}$. El art. 107 de la Constitución de Weimar (1919) continuaba el modelo prusiano de la jurisdicción contencioso-administrativa, exigiendo a los Estados la constitución de tribunales de este orden para la defensa de los particulares frente a los actos administrativos ilegales. Tras el ominoso período nacional-socialista, el eje del moderno asentamiento de esta jurisdicción parte de la tutela judicial garantizada a toda persona en el art. 19.IV de la Ley Fundamental de Bonn de 1949 y se desarrolla en la Ley de la Jurisdicción Administrativa de $1960^{38}$.

37 El siglo XX en Alemania contempla su derrota en la Primera Guerra Mundial plasmada en el Tratado de Versalles (1919), que determinará el fin del II Reich y la puesta en marcha de la República Federal regida por la Constitución de Weimar (1919). Conforme a ese sistema político, como es sabido, se produjo la designación de Hitler como canciller (1933), que llevaría a la formación del III Reich. Tras la Segunda Guerra Mundial, se constituyeron, de una parte, la República Federal de Alemania integrada por 11 Estados conforme al modelo democrático de la Ley Fundamental de Bonn (1949) y, de otra parte, la República Democrática de Alemania compuesta por 5 Estados, que seguía el modelo totalitario soviético (1950). Como se recordará, la reunificación de los 16 Estados en la República Federal de Alemania se produjo tras la caída del telón de acero en 1990.

38 Para una traducción al español de la Ley de la Jurisdicción Administrativa alemana de 1960, véase P. Aberasturi, coord. (2009), traducción que va precedida de interesantes estudios sobre el sistema alemán y otras experiencias comparadas. Durante algún tiempo se desarrolló un debate sobre la conveniencia de unificar la jurisdicción contencioso-administrativa con la social y la tributaria, contándose los proyectos de la Escuela de Speyer (1969), de la Comisión de Coordinación (1978) y del Gobierno Federal (1982). Pero finalmente parece que la sobrecarga de asuntos en estos órdenes jurisdiccionales ha dado al traste con tales iniciativas. 


\section{Organización}

La planta jurisdiccional está integrada por tres tipos de órganos colegiados: a) los tribunales administrativos competentes en primera instancia, que se constituyen por los Estados y admiten la formación de juez único en asuntos sencillos; b) el Tribunal Administrativo Superior de cada Estado, que atiende las apelaciones; y c) el Tribunal Federal Administrativo, al que se atribuye el recurso de casación, además de algunas competencias directas en asuntos considerados de particular importancia.

Siguiendo la tradición del sur de Alemania, los tribunales administrativos, al igual que los de otros órdenes jurisdiccionales, están integrados por tres jueces profesionales y dos jueces honorarios ${ }^{39}$. Estos últimos tienen reconocida su participación "en el juicio oral y en la deliberación de la sentencia con los mismos derechos que los jueces profesionales" (Ley Jurisdiccional: art. 19) ${ }^{40}$. Entre las ventajas derivadas de la presencia de personas sin cualificación profesional, suele aducirse que este mecanismo participativo permite vencer la rutina obligando a los jueces profesionales a razonar en términos comprensibles para la ciudadanía. No obstante, el escaso nivel técnico de los jueces honorarios parece haber determinado la desaparición de los mismos en los tribunales superiores conforme a la legislación de los Estados.

Una figura cercana a la del antiguo comisario del gobierno francés es la del representante del interés federal, que compete designar al Gobierno Federal y que dispone de la capacidad de intervenir en los procedimientos del Tribunal Federal Administrativo dando su opinión sobre los asuntos con arreglo a las instrucciones de su mandante (Ley Jurisdiccional: art. 35). También en los restantes tribunales administrativos puede existir el denominado "representante del interés público", que propiamente representa el interés del Estado correspondiente con carácter general o para casos determinados (art. 36).

En el art. 40 de la Ley Jurisdiccional de 1960 se contiene la llamada cláusula general de lo contencioso-administrativo:

"La vía jurisdiccional contencioso-administrativa es procedente en todos los asuntos de Derecho público no constitucionales, cuando el asunto no está atribuido expresamente por una ley federal a otro tribunal. Los

39 El número de jueces administrativos profesionales es de unos 2.000, cifra elevada por comparación con otros países que, además, debería incrementarse con los 600 jueces de la jurisdicción tributaria, dado que ésta no se encuentra separada en otras experiencias.

40 Se trata de una participación ya afianzada y abierta para todo alemán mayor de 25 años y con capacidad de desempeñar cargos públicos, que puede ser incluido en las listas de candidatos aprobadas con mayoría reforzada por los municipios, llevándose a cabo la elección cada cinco años por comisiones de personas honorables designadas por el Estado para cada tribunal. 
asuntos de Derecho público pueden atribuirse por ley estatal y en el ámbito del correspondiente ordenamiento estatal a otro tribunal."

Estamos pues ante una jurisdicción general con referencia a los asuntos de Derecho público ${ }^{41}$. Todos los asuntos jurídico-públicos pueden ser sometidos al control judicial contencioso-administrativo, sin que sea exigible identificar ni impugnar un acto u otra medida de los entes públicos. Pero el litigio debe cuestionar efectos de Derecho público, concepto en el que se incluye toda relación jurídica con un sujeto que de cualquier manera sea titular de poder público. Se excluyen: a) los asuntos no jurídicos relacionados con actos de contenido graciable o propiamente de gobierno; b) los actos constitucionales correspondientes a los sujetos que participan directamente en la vida constitucional; y c) las cuestiones atribuidas a diferente jurisdicción en la propia Ley Jurisdiccional o en otras leyes, como sucede en materia de expropiación y responsabilidad.

\section{El requisito de la lesión jurídica de derechos individuales}

Frente a la concepción objetiva de raigambre francesa, la legitimación en el contencioso-administrativo alemán se rige por criterios subjetivos. Así, el acceso a la jurisdicción, el objeto del proceso, el enjuiciamiento y el pronunciamiento del tribunal se centran en averiguar si ha existido lesión jurídica en derechos individuales. El concepto de lesión jurídica subjetiva equivale al perjuicio en los derechos del particular como consecuencia de una medida administrativa ilegal. Pero ni esa medida ni desde luego un previo acto administrativo son exigibles para acceder a la jurisdicción, cuya competencia gira en torno a la noción de asuntos de Derecho público. Las formas jurídicas en las que puede concretarse una relación jurídico-pública son, en consecuencia, variadas, comprendiendo el acto administrativo, el contrato, el reglamento, pero también la simple actuación administrativa, ya sea directamente material o se exprese en declaraciones, informaciones o cualesquiera documentos; todos los modos de actuación del poder público que se presenten en la realidad son susceptibles del control contencioso-administrativo. En este contexto, el concepto de Administración no es necesario, pues su presencia sólo es indicativa para el contencioso-administrativo, siendo decisiva la lesión de derechos individuales por el poder público, sea cual sea la forma adoptada por éste ${ }^{42}$.

${ }^{41}$ De ahí que en la práctica carezca de importancia la competencia subsidiaria de la jurisdicción ordinaria establecida en el art. 19.4 de la Ley Fundamental ("Si no hubiere otra jurisdicción competente para conocer del recurso, quedará abierta la vía judicial ordinaria").

42 Conforme a este planteamiento, si la medida administrativa no causara una lesión individual, la protección jurídica se agotaría en la solicitud a la Administración de que ejerza los medios de control interno de la legalidad objetiva. No obstante, paulatinamente el sistema contencioso-administrativo alemán parece ir abriéndose para cubrir los espacios tradicionalmente relegados al control administrativo interno. 
Para la admisibilidad del proceso, el demandante debe hacer valer su lesión y expresar su voluntad de obtener un resarcimiento subjetivo (Ley Jurisdiccional de 1960: art. 42). La cuestión del grado o la intensidad con que ha de hacerse valer la lesión pone de manifiesto la importancia del requisito, que no se puede entender como un adorno o muletilla en las demandas. Por lo común se emplea el criterio de la posibilidad, conforme al cual no basta la mera declaración de que se ha producido una lesión, sino que ésta ha de ser, al menos, posible, aunque no llega a exigirse la manifestación efectiva de la lesión jurídica.

Importa destacar que el requisito consiste en hacer valer la lesión jurídica de derechos propios, de manera que la posición singular del afectado debe ser claramente reconocible. En la protección judicial se incluyen los derechos subjetivos y en general los intereses jurídicamente relevantes, que se presentan cuando la norma abre al particular una posición jurídica concreta que permite reconocer un interés propio junto al interés de la generalidad de los ciudadanos. No bastan los reflejos normativos meramente fácticos, como el interés científico, cultural, político, religioso o ideológico. Debe tratarse de los intereses individuales que el ordenamiento jurídico reconoce como dignos de protección judicial. En tal sentido, la defensa de intereses difusos se ha mostrado altamente problemática: en el ámbito vecinal sólo se admite la legitimación del particular si goza de una posición singular para defender un bien propio, como la propiedad, la salud o la vida; la legitimación de las asociaciones presenta fuertes condicionantes, pues se niega en el caso de las llamadas asociaciones "de interés" para hacer valer los derechos o intereses de sus miembros; y en las asociaciones "altruistas" se exige el reconocimiento legal de su legitimación en defensa de fines públicos ${ }^{43}$.

\section{Acciones y justicia cautelar}

En el contencioso-administrativo alemán es preciso utilizar la acción específicamente necesaria, distinguiéndose las siguientes modalidades: a) acción de anulación, que procede frente a un acto de gravamen en un determinado plazo, previo agotamiento de la vía administrativa; $b$ ) acción de condena encaminada a que el poder público conceda una pretensión a la que el demandante tiene derecho, previo requerimiento y agotamiento de la vía administrativa en determinado plazo; c) acción declarativa, que permite declarar la existencia o inexistencia de una relación jurídica, declarar la nulidad de un acto administrativo y otros aspectos sin sujeción a plazo ni

43 No obstante, la legitimación activa y el alcance del control judicial en algunos sectores de actuación administrativa, como ocurre en materia de protección del medio ambiente y particularmente en los procedimientos de evaluación de impacto ambiental, han experimentado considerables ampliaciones conforme a las exigencias establecidas en la normativa europea. Así se ha hecho valer por el TJUE en los casos Bund für Umwelt und Naturschutz Deutschland (EU:C:2011:289) y Comisión c/ Alemania (EU:C:2015:683). 
necesidad de agotar la vía administrativa, aunque antes de ejercerla debe solicitarse en vía administrativa la declaración pretendida; d) acción prestacional general, cuyo objetivo es obtener cualquier prestación no consistente en un acto administrativo, por lo que se considera el cierre del sistema pues garantiza con carácter subsidiario que ninguna lesión administrativa queda sin fiscalizar, pudiendo comprender objetos tan variados como actuaciones materiales, declaraciones de conocimiento, informaciones, inmisiones o retractaciones, y aplicándose un ventajoso régimen procesal, dado que su ejercicio no se sujeta a plazo y no requiere de un acto administrativo previo; y e) recurso contra reglamentos, cuya generalización constituyó una novedad de la Ley Jurisdiccional de 1960, pues anteriormente sólo se preveía en Baviera y algunos Estados del sur, aunque, en contrapartida, esta acción únicamente procede si está permitida en la legislación de los Estados, exigiéndose en todo caso que el actor pueda derivar un perjuicio directamente de la norma o indirectamente de su aplicación, si bien no es preciso observar ningún plazo ni agotar previamente la vía administrativa.

La tutela cautelar se considera elemento esencial para lograr la efectividad del derecho a la tutela judicial reconocido en el art. 19 de la Ley Fundamental ${ }^{44}$. Puede ejercerse en las acciones anulatorias mediante la suspensión del acto administrativo recurrido, que se aplica con carácter automático salvo en materia tributaria y otros casos establecidos por ley (energía, seguridad laboral, disciplina militar); sistema que recibe críticas particularmente en relación con los supuestos de relaciones multilaterales al beneficiar a uno de los particulares afectados. En las acciones de condena y de tipo prestacional, la medida cautelar típica, siempre que no pueda aplicarse la suspensión, es la orden provisional de contenido positivo, cuya función esencial es asegurar el éxito de la pretensión y que, sobre la base común de una situación de peligro del derecho invocado, admite dos modalidades: a) asegurar una pretensión individual ante el riesgo de que el derecho pueda malograrse o resultar esencialmente perjudicado; o b) regular una relación jurídica para evitar que pueda experimentar una desventaja jurídica.

\section{EL CONTROL JURÍDICO DE LAS INSTITUGIONES DE LA UNIÓN EUROPEA}

\section{El contencioso de la Unión}

El sistema judicial de la Unión Europea es el resultado de un proceso pragmático. Como destacó en nuestra doctrina M. Díez de Velasco (1986: 648), dicho sistema comprende las funciones propias de una jurisdicción internacional y las co-

$44 \quad$ Véase ampliamente el trabajo de J. BARNÉs (1990) sobre la tutela cautelar y la celeridad en la justicia administrativa alemana. 
respondientes a una jurisdicción interna. Conforme a las previsiones del vigente Tratado de Funcionamiento de la Unión Europea, las tres grandes vías de ejercicio de esas funciones son: a) el recurso por incumplimiento contra un Estado miembro interpuesto bien por la Comisión (art. 258) bien por otro Estado miembro (art. 259), a fin de garantizar la observancia de las obligaciones estatales que incumben en virtud de los tratados constitutivos; b) el recurso de anulación, accesible a los Estados miembros y a las instituciones de la Unión, pero también a cualquier persona interesada, para asegurar la legalidad de los actos de las instituciones de la Unión (art. 263); y c) la cuestión prejudicial a iniciativa de los órganos jurisdiccionales nacionales, que asegura la primacía de todos los contenidos del Derecho de la Unión Europea, originario y derivado $(\operatorname{art} .267)^{45}$.

Aquí nos interesa referirnos específicamente a la segunda de esas vías, es decir, al sistema de reacción jurídica diseñado para asegurar la observancia del Derecho de la Unión Europea por las instituciones comunes, sistema al que denominamos contencioso de la Unión. En el Tratado de Funcionamiento, son medios de ejercicio de dicho contencioso, junto al citado recurso de anulación (art. 263), los restantes recursos directos: el recurso de plena jurisdicción contra sanciones siempre que esté previsto en el correspondiente reglamento (art. 261), el recurso por inactividad (art. 265), la acción indemnizatoria por responsabilidad extracontractual (art. 268), el contencioso de la función pública (art. 270) y el contencioso derivado de cláusulas compromisorias (art. 272) ${ }^{46}$.

Inicialmente, el ejercicio de todas las funciones jurisdiccionales se concentró en el Tribunal de fusticia. Sin embargo, el incremento del número de asuntos, así como la diferente índole de los mismos, ha llevado a la creación de nuevos órganos jurisdiccionales que permiten identificar una planta propia del contencioso de la Unión. Así, la previsión del Tribunal de Primera Instancia en el Acta Única (1986) se orientaba ya a concentrar en este órgano el ejercicio general de la jurisdicción administrativa junto a otras funciones. Tras las reformas llevadas a cabo en el Tratado de Niza

45 Si quisiéramos precisar el alcance de cada una de las vías enunciadas, habría abundantes matices y complementos que incorporar al anterior esquema. Pero a efectos de nuestro discurso, basta con destacar que la arquitectura básica del sistema jurisdiccional de la Unión está integrada por esas tres columnas: una, sosteniendo directamente los tratados frente a los Estados (recurso por incumplimiento), otra, garantizando la legalidad general en la actuación de las instituciones comunes (recurso de anulación), y la tercera asegurando la primacía del Derecho de la Unión (cuestión prejudicial).

46 Sobre el sistema jurisdiccional de la Unión Europea, véanse: GARCÍA DE ENTERRÍA, E. (1986), EVERLING, U. (1993), ORTEGA, M. (1999), GARCÍA LUENGO, J. (2004), GALERA RODRIGO, S. (2005) y LÓPEZ RAMÓN, F. (2007). 
(2001), el mismo tribunal se consolidó como juez general del contencioso comunitario, con la denominación de Tribunal General tras el Tratado de Lisboa $(2007)^{47}$.

No obstante, el contencioso de la Unión no se constituye como una organización totalmente separada, puesto que las resoluciones del Tribunal General son susceptibles de recurso de casación ordinario o extraordinario ante el Tribunal de Justicia (Tratado de Funcionamiento: art. 256). Precisamente a través de una de las modalidades del recurso de casación extraordinario, el Tribunal de Justicia resulta competente para examinar las resoluciones del Tribunal General relativas a recursos contra resoluciones de los tribunales especializados, "en caso de riesgo grave de que se vulnere la unidad o la coherencia del Derecho de la Unión" (art. 256.2). De manera que la planta orgánica del contencioso-administrativo conecta plenamente con el sistema jurisdiccional de la Unión en su conjunto ${ }^{48}$.

En el Tribunal General tiende a concentrarse el ejercicio genérico del contencioso-administrativo de la Unión. Tal tendencia pudiera verse acentuada en el futuro dada la amplia remisión al Estatuto del Tribunal de Justicia para "establecer

47 La importancia de las reformas del Tratado de Niza en el sistema jurisdiccional de la Unión Europea puede comprobarse en diversos autores: RASMUSSEN, H. (2000), WEILER, J.H.H. (2002), ALONSO GARCÍA, R. \& SARMIENTO, D. (2003), VESTERDORF, B. (2003) y ARNULL, A. (2005). Como enseguida explicaremos, en Niza, junto al Tribunal General, se puso en marcha un cierto proceso de especialización contencioso-administrativa, permitiéndose la creación de salas jurisdiccionales (tribunales especializados en Lisboa), aunque por ahora sólo se ha constituido como tal el Tribunal de la Función Pública (que ya ha sido también suprimido, como enseguida veremos). Paralelamente, en determinados sectores de actuación, se han creado las llamadas salas de recurso, que son órganos independientes encargados de resolver ciertos recursos en vía administrativa, los cuales, al margen de que en el futuro pudieran llegar a ser configurados como órganos judiciales especializados, forman parte, sin duda, del conjunto de garantías jurídicas establecidas para imponer la observancia del Derecho de la Unión por parte de las instituciones comunes.

48 El carácter de juez administrativo no impide el ejercicio por el Tribunal General de otras funciones más cercanas a las propias de una jurisdicción constitucional. En relación con ello, quizá sería conveniente matizar el alcance de la comparación que suele establecerse entre el contencioso de la Unión y el contencioso de origen francés (DÍEZ DE VELASCO, M. 1986: 652; GARCÍA DE ENTERRÍA, E. 1986: 660). Es evidente que en el Tratado de Funcionamiento, al establecerse el remedio clave del recurso de anulación "por incompetencia, vicios sustanciales de forma, violación del presente Tratado o de cualquier norma jurídica relativa a su ejecución, o desviación de poder" (art. 263, apartado $2^{\circ}$ ), se ha tenido presente la experiencia del Conseil d'État. Sin embargo, ese paralelismo en los aspectos funcionales es limitado, puesto que el recurso de anulación puede ser empleado contra las normas comunitarias de origen parlamentario, llegándose, así, a una suerte de control difuso de su "constitucionalidad" o simplemente a un control de "constitucionalidad" compartido con el Tribunal de Justicia. Por añadidura, la planta jurisdiccional de la Unión resulta más cercana al modelo de revisión judicial de corte anglosajón. Los mismos jueces deciden todos los asuntos atribuidos a la competencia del Tribunal General. No se advierte, dentro de la organización de dicho Tribunal, ninguna tendencia a especializar a algunas de sus salas en las materias del contencioso-administrativo de la Unión. Ni tan siquiera en la atribución del conocimiento de determinados asuntos a las diferentes formaciones del Tribunal General (pleno, gran sala, sala de cinco jueces, juez ponente) parecen tenerse en cuenta criterios relativos al carácter "administrativo" o "constitucional" de los litigios. 
que el Tribunal General sea competente en otras categorías de recursos" (Tratado de Funcionamiento: art. 256.1). La remisión quizá podría servir incluso para configurar una cláusula general de control contencioso, por el Tribunal General, de todas las modalidades de actividad, inactividad o vía de hecho de las instituciones comunes, conforme a las exigencias del derecho a la tutela judicial efectiva de los derechos subjetivos y los intereses legítimos.

\section{Los tribunales especializados}

Las tradiciones jurídicas de los Estados miembros de la Unión Europea permiten considerar como una conquista histórica aplicable a la organización común la afirmación del principio de unidad jurisdiccional, que impone la generalización de jueces y tribunales ordinarios y la paralela supresión de los jueces y tribunales excepcionales y especiales ${ }^{49}$. En tal sentido, las posibilidades de especialización del contencioso de la Unión parecen haber respetado ese principio de unidad jurisdiccional al vincularse nítidamente a la organización judicial general. Así, la previsión de que pudieran crearse salas jurisdiccionales (judicial panels, chambres juridictionnelles) fue incluida por el Tratado de Niza (2001) en la sección del Tratado CE dedicada al Tribunal de Justicia, ubicación conservada en el Tratado de Funcionamiento UE aunque con la nueva denominación de tribunales especializados (art. 257). Los tribunales especializados se conciben como órganos judiciales competentes en determinadas materias, cuya creación corresponde al Parlamento Europeo y al Consejo conforme al procedimiento legislativo ordinario, previa intervención siempre de la Comisión y el Tribunal de Justicia.

Hay, en todo caso, en esta materia, una amplia remisión a la discrecionalidad del Consejo con el Parlamento. De forma que corresponde a las instituciones generales de la Unión decidir libremente la composición y el alcance de las competencias de cada tribunal especializado. No obstante, tal libertad de configuración aparece limitada por la necesidad de respetar algunas reglas específicas establecidas en los diferentes apartados del art. 257 del Tratado de Funcionamiento: a) se prevé una completa especialización de estos tribunales, ya que las competencias que se les atribuyan han de referirse al conocimiento "en primera instancia de determinadas categorías

49 Para un tratamiento general sobre el principio de unidad jurisdiccional, cabe remitir a ANDRÉS IBÁÑEZ, P. \& MOVILLA ÁLVAREZ, C. (1986: 178-184). El principio no se opone a la constitución de órganos judiciales especializados por razón de la materia, siempre que respondan a la necesidad de proporcionar una mejor administración de justicia y estén claramente integrados en la organización judicial general. En relación con el control judicial de los distintos ámbitos de actuación de la Unión Europea, ello significa que las decisiones en materia de especialización jurisdiccional han de vincularse a los poderes generales de la misma Unión. En otro caso, se correría el peligro de que cada sector promoviera la constitución de su propio órgano judicial e incluso de que llegara a intervenir en la selección de los correspondientes jueces o en el establecimiento de las reglas procesales. 
de recursos interpuestos en materias específicas"; b) las resoluciones de los tribunales especializados deben de ser susceptibles de recurso ante el Tribunal General, aunque se permite al Parlamento Europeo y al Consejo conjuntamente decidir entre la vía del "recurso de casación limitado a las cuestiones de Derecho" y el "recurso de apelación referente también a las cuestiones de hecho"; c) si bien la composición de cada tribunal especializado corresponde a la decisión del Parlamento Europeo y el Consejo, los miembros de dichos tribunales han de ser elegidos "entre personas que ofrezcan absolutas garantías de independencia y que posean la capacidad necesaria para el ejercicio de funciones jurisdiccionales", imponiéndose así el monopolio de las profesiones jurídicas para formar parte de un tribunal especializado; y d) se ordena respetar la potestad de los tribunales especializados de establecer, junto con el Tribunal de Justicia, el régimen del procedimiento a observar en los asuntos de los que deban conocer, potestad característica del sistema judicial de la Unión, sin perjuicio de que la aprobación última del correspondiente reglamento esté atribuida al Consejo.

La consideración de las anteriores reglas permite afirmar que el Tratado de Funcionamiento configura a los tribunales especializados como órganos judiciales de pleno derecho. La remisión de la exacta factura de los mismos al Derecho derivado no implica, como hemos visto, una ausencia de garantías en el Tratado. Concretamente, la especialización no entraña pérdida de la naturaleza jurisdiccional, pregonada en su misma denominación y asegurada esencialmente mediante el otorgamiento de funciones jurisdiccionales exclusivas en el ámbito de sus competencias y asimismo por la esencial previsión de jueces independientes a su servicio. Las funciones del contencioso interno de la Unión se reparten así entre el Tribunal General y los tribunales especializados que puedan llegar a constituirse.

A finales de 2004 se creó el primero (y por ahora único, además de efímero) de esos tribunales especializados (entonces, salas jurisdiccionales), el Tribunal de la Función Pública de la Unión Europea, competente para resolver en primera instancia los litigios entre las instituciones comunes y sus agentes. En realidad, conocía de los asuntos en única instancia, dado que contra sus resoluciones se optó por permitir únicamente recurso de casación ante el Tribunal General. Como novedad, este órgano judicial no presentaba el peligro de asumir un carácter asambleario que pudiera derivar de la exigencia de un juez por cada Estado miembro, pues se componía de siete jueces designados por un período de seis años, a cuyo término eran reelegibles. El nombramiento de los mismos trataba de garantizar su idoneidad profesional a través del dictamen de un comité de personalidades del Derecho sobre los candidatos libremente presentados. El funcionamiento del nuevo tribunal se apoyó en los servicios del Tribunal de Justicia y del Tribunal General, pero podía disponer de funcionarios y agentes adscritos. Asimismo, el procedimiento a seguir se remitía en términos generales al establecido en el Estatuto del Tribunal de Justicia, ordenándose 
normalmente en una fase escrita (demanda y contestación) y una fase oral (o escrita, por acuerdo de las partes). En todo caso, el Tribunal de la Función Pública ha sido disuelto en 2016, atribuyéndose sus competencias al Tribunal General, cuyo número de jueces fue simultáneamente ampliado (Reglamento UE 2015/2422).

\section{Las salas de recurso}

Un fenómeno que guarda, sin duda, relación con el establecimiento de órganos judiciales especializados es el de las denominadas salas de recurso (boards of appeal, chambres de recours), que se han establecido en diversos reglamentos de la Unión ${ }^{50}$. Concretamente, antes de que los tribunales especializados fueran previstos, se constituyeron salas de recurso en las agencias competentes en materia de marcas comunitarias (1993) y obtenciones vegetales (1994). Después del Tratado de Niza (2001), se ha generalizado la previsión de nuevas salas de recurso, por ejemplo, en las agencias competentes en materia de seguridad aérea (2002), sustancias y preparados químicos (2006), reguladores de la energía (2009) o supervisión financiera (2010). Las mismas competencias materiales implicadas en cada uno de esos supuestos parecen proporcionar suficiente base jurídica para la creación de las salas de recurso, cuyo objeto es ofrecer garantías de imparcialidad en la resolución de los recursos administrativos planteados por los particulares frente a los actos de aplicación del Derecho de la Unión encomendados a determinados organismos. Objeto plausible, que, sin embargo, no debiera llevar a confundirlas con los tribunales especializados. Las salas de recurso proporcionan garantías de objetividad en la vía administrativa, pero no forman parte de la planta jurisdiccional de la Unión. Por ello, cabe oponerse a sus resoluciones en vía judicial ${ }^{51}$.

50 Véanse la detallada exposición de ARANA GARCÍA, E. (2016).

51 Las salas de recurso de la Oficina de Armonización del Mercado Interior (OAMI) parecen constituir el modelo en buena medida seguido en otros sectores, aunque ARANA, E. (2016: 119) propugna el establecimiento, para todas las salas de recurso, de reglas comunes que el mismo autor ha tratado de identificar (ibidem: 104-117). En cualquier caso, las salas de recurso de la OAMI proporcionan una protección jurídica adaptada a la particularidad del Derecho de marcas. Cada sala se compone de tres miembros, dos de los cuales al menos deben ser juristas, correspondiendo los nombramientos al Consejo sobre la base de ternas elaboradas por la Oficina. Su mandato es por cinco años, período durante el que no podrán ser relevados de sus funciones, salvo por motivos graves y por acuerdo tomado a tal fin por el Tribunal de Justicia. Tienen garantizada la independencia, sin estar sujetos en sus decisiones por instrucción alguna. El objeto de los recursos se limita a los actos de los órganos de la OAMI relativos a la marca comunitaria. El recurso tiene efecto suspensivo, estando legitimada para interponerlo cualquiera de las partes en el procedimiento cuyas pretensiones no hayan sido estimadas, dentro del plazo general de dos meses desde la notificación de la resolución recurrida, disponiéndose de dos meses más para exponer los motivos del recurso. El órgano que dictó el acto recurrido dispone del plazo de un mes para estimar el recurso, si lo tuviere "por admisible y fundado", potestad esta que se denomina de "revisión prejudicial", puesto que las salas de recurso no tienen naturaleza judicial, como hemos visto. En todo caso, de no estimarse el recurso por el órgano administrativo activo, tras seguir un flexible procedimiento contradictorio entre las partes enfrentadas, a las que se invita 
En cuanto al futuro de las salas de recurso existentes y su eventual configuración como tribunales especializados, poco parece poder aventurarse. No es una cuestión que afecte necesariamente a la buena factura orgánica del contencioso de la Unión. El Tratado de Niza (2001) puso las bases necesarias para que las instituciones de la Unión Europea puedan adaptar la planta del contencioso a las necesidades de especialización judicial advertidas, pero reflexiones sobre la calidad y eficacia de la actuación de tales órganos administrativos (las salas de recurso) habrán de ser las que determinen las eventuales decisiones de transformarlas en órganos judiciales (tribunales especializados).

\section{Eficacia del sistema}

El sistema que acabamos de describir se caracteriza por la notable incorporación de criterios de eficacia. Dentro del cumplimiento de unas garantías ineludibles, el pragmatismo ha dominado la construcción del control jurídico de las instituciones de la Unión Europea. Un mismo orden de tribunales entiende de todos los litigios que pueden plantearse, no sólo para asegurar el respeto del Derecho de la Unión por las instituciones comunes, sino también para garantizar su cumplimiento por los Estados miembros y los particulares. Ahora bien, dentro de ese sistema general, se ha optado por especializar al Tribunal General en el contencioso de la Unión y permitir mayores niveles de especialización, cuando sean necesarios, mediante la constitución de tribunales especializados como el desaparecido Tribunal de la Función Pública. El sistema se completa con la creación, en determinados sectores, de las salas de recurso, órganos de carácter independiente que garantizan la calidad jurídica en la resolución de los recursos administrativos y que pudieran llegar a ser configurados como tribunales especializados.

No se trata de un sistema diseñado como modelo para los Estados. Sin embargo, presenta unos rasgos que lo hacen atractivo en la óptica de las experiencias nacionales. La especialización judicial y la objetividad del procedimiento administrativo de recurso son, así, características que fácilmente pueden ser aplicadas por los Estados europeos con la finalidad de descargar las vías ordinarias de control jurídico del ejecutivo.

cuantas veces sea necesario a presentar observaciones, la sala fallará sobre el recurso, pudiendo bien ejercer las competencias de la instancia que dictó la resolución impugnada, bien devolver el asunto a dicha instancia para que le dé cumplimiento. Contra las resoluciones de las salas de recurso, al proceder de órganos administrativos de un organismo de la Unión, puede emplearse el ordinario recurso de anulación previsto con carácter general en el Tratado de Funcionamiento UE (art. 263). La competencia para conocer del recurso corresponde al Tribunal General, en su condición ya resaltada de juez general del contencioso de la Unión, abriéndose posteriormente la posibilidad de interponer recurso de casación ante el Tribunal de Justicia. 


\section{RACIONALIZACIÓN, FLEXIBILIDAD, ESPECIALIZACIÓN Y COLABORACIÓN EN EL MODELO EUROPEO DE GONTROL JURÍDICO DEL PODER EJEGUTIVO}

Llegados al final de este denso recorrido por las jurisdicciones administrativas europeas, trataremos de conectar con los planteamientos iniciales: ¿cabe hablar de un modelo europeo de control jurídico del ejecutivo? ¿qué características podrían identificarlo?

La existencia de unas garantías jurídicas básicas equiparables del justiciable europeo enfrentado al poder público es ya un lugar común en la literatura jurídica especialmente como consecuencia de la importantísima labor desempeñada por el TEDH. No merece la pena pues insistir en esos aspectos: en la actualidad todos los modelos europeos aparecen condicionados e incluso conformados por el conjunto de garantías que tesoneramente ha ido identificando el tribunal de Estrasburgo. La legitimación, el sometimiento general de los poderes administrativos, el control de la discrecionalidad, la imparcialidad de los juzgadores, los medios de prueba, la ejecución de sentencias y tantas otras cuestiones se benefician de esa benemérita jurisprudencia, sin perjuicio de los problemas que todavía subsisten en cuanto a la plenitud de efectos de las sentencias del TEDH frente a las jurisdicciones nacionales.

Ahora bien, la esencialidad de tales garantías no basta para construir un modelo de control jurídico del ejecutivo, que debe asumir también la solución de problemas estructurales para ofrecer una verdadera justicia: argumentada, previsible, rápida, eficaz y prestigiosa. Una justicia que habitualmente ofrezca, en tiempos breves, respuestas fundadas de contenido similar ante idénticas cuestiones, con capacidad para imponer sus declaraciones, que habrían de ser generalmente aceptadas y estimadas por el conjunto de sus destinatarios, especialmente por los integrantes de las profesiones jurídicas.

Cuando hablamos de un modelo que pudiera asumir los anteriores retos, no estamos pensando en un modelo cerrado o completo como el que podría ofrecer cualquiera de las experiencias aquí consideradas. No se trata de identificar el modelo preferible a fin de que pueda ser adoptado o seguido en otros Estados. Mucho menos podemos pensar en la elaboración de un modelo teórico que hubiera de imponerse en Europa. En realidad el modelo europeo ha de referirse a algunos rasgos característicos que cabe diseñar como comunes, siempre actuando con pragmatismo para resolver los problemas identificados en el funcionamiento de los variados sistemas 
nacionales. En tal sentido, el conocimiento y la valoración crítica del propio sistema nacional podría constituir nuestro punto de partida común ${ }^{52}$.

Nos situamos pues en un contexto de profundización en los elementos positivos de cada trayectoria estatal y asimismo dentro de la permanente vinculación -anteriormente recordada- a las garantías comprendidas en el derecho humano al proceso equitativo. Desde los firmes cimientos, por tanto, que proporcionan las experiencias nacionales revisadas y actualizadas por la jurisprudencia transnacional, cabe identificar como rasgos estructurales comunes de un modelo europeo de control jurídico del ejecutivo las ideas de racionalización, flexibilidad, especialización y colaboración que pasamos a caracterizar.

La racionalización significa que no ha de confiarse en la formación espontánea de los sistemas nacionales. Los avances jurisprudenciales han de traducirse en reformas normativas que eviten las dudas aplicativas. La caracterización de un órgano como administrativo o judicial, si ciertamente ha de responder a criterios jurídicos fundados, es preferible que sea resuelta en la ley. En todo caso, las reformas de los sistemas de justicia administrativa conviene que sean previamente diseñadas en informes detallados elaborados con amplia audiencia de los diversos profesionales jurídicos. Debate abierto conducido por juristas dotados de autoridad en el sentido romano.

La flexibilidad como característica de un modelo impone su adaptabilidad a situaciones variables. No hay un conjunto fijo e inamovible de problemas a resolver; antes bien, los desafíos están en permanente proceso de transformación. Ha de asumirse que los administrados son muy libres, en función de sus derechos e intereses, de canalizar las demandas de justicia en relación con el poder público: migraciones, medio ambiente, tráfico automóvil, educación o cualquier otro sector de actividad administrativa pueden determinar picos de intervención judicial. El sistema tiene que diseñarse pues con alto grado de adaptabilidad a los requerimientos de la sociedad: legitimación, vías administrativas, soluciones tipo...

La especialización jurisdiccional es una necesidad ampliamente sentida como bien se ha puesto de relieve al examinar los grandes modelos europeos: el mismo caso británico, tan ligado a la idea original de la comunidad e igualdad de jueces, ha tenido que establecer unos órganos judiciales especializados en impartir la justicia

52 Particularmente tengo la impresión de que las doctrinas británica, francesa y alemana, cada una por separado y en términos generales, consideran coherentes y adecuados sus propios sistemas nacionales de justicia administrativa. No estoy seguro, sin embargo, de que una apreciación similar se pudiera constatar en otras experiencias. Con referencia concreta a España, diría que entre nosotros no se estila o se estila poco el diálogo entre la justicia y la doctrina: me parece que generalmente ambas se ignoran, cuando no se menosprecian recíprocamente. 
administrativa. Ahora bien, lo anterior no es sino una solución racional en la tramitación de los asuntos, por sí sola equivalente a la distribución por materias que puede hacerse entre las secciones de un mismo tribunal. La verdadera especialización es la que aporta el conocimiento profundo del Derecho público, es decir, la que se hace valer en el acceso a la judicatura y en las sucesivas promociones de jueces y magistrados.

Finalmente, en el modelo europeo de control jurídico del ejecutivo, se impone la colaboración de los remedios judiciales con los administrativos. Particularmente importante resultaría en tal sentido dar un nuevo impulso a las tradicionales vías de recurso administrativo, que en experiencias como la española tienen ya escasa utilidad, tanto para la Administración como para el administrado, dado que han perdido el carácter de privilegio que las hacía atractivas para la primera y no han alcanzado el contenido de garantía que impulsaría su empleo por el segundo. En la opción entre el mantenimiento de una institución ineficaz o la búsqueda de mecanismos que pudieran revitalizarla, parece necesario decantarse por la última alternativa, entre cuyas ventajas cabe identificar la posibilidad de garantizar un control fiable, rápido y barato de la actividad administrativa ${ }^{53}$.

53 Véanse en esta línea el conjunto de estudios recogidos en LÓPEZ RAMÓN, F. (2016), que constituyen las actas del XI Congreso de la Asociación Española de Profesores de Derecho Administrativo, convocado justamente con el título "Las vías administrativas de recurso a debate". 


\section{BIBLIOGRAFÍA}

ABERASTURI, P., coord. (2009), Ley de la fusticia Administrativa alemana: análisis comparado y traducción, Buenos Aires, Abeledo Perrot, 224 pp.

ALONSO GARCÍA, R. \& SARMIENTO, D. (2003): "Los efectos colaterales de la Convención sobre el futuro de Europa en la arquitectura judicial de la Unión: ¿hacia una jurisdicción auténticamente constitucional europea?", en Revista de Estudios Políticos núm. 119, pp. 111-138.

IBÁÑEZ, A., PERFEGTO \& MOVILLA ÁLVAREZ, C. (1986): El poder judicial, Madrid, Tecnos, $416 \mathrm{pp}$.

ARANA GARCÍA, E., (2016): "Los recursos administrativos en la Unión Europea: hacia un modelo común de justicia administrativa", en F. LÓPEZ R. (coord.), Las vías administrativas de recurso a debate, Madrid, INAP, pp. 67-121.

ARNULL, A. (2005): "From bit part to starring role? The Court of Justice and Europe's Constitutional Treaty”, en Yearbook of European Law núm. 24, pp. 1-25.

JEAN MARIE, A., \& FROMONT, M. (1971): Les recours contre les actes administratifs dans les pays de la Communauté Economique Européenne. Allemagne, Belgique, France, Italie, Luxembourg, Pays-Bas, Paris, Dalloz, 473 pp.

BARCELONA LLOP, J., (2016): "Las vías administrativas de recurso: panorama desde la jurisprudencia del Tribunal Europeo de Derechos Humanos", en F. LÓPEZ, R., (coord.), Las vías administrativas de recurso a debate, Madrid, INAP, pp. $27-66$.

BARNÉS VÁZQUEZ, J., (1993): "La tutela judicial efectiva en la Grundgesetz", en BARNÉS VÁZQUEZ, J. (coordinador), La justicia administrativa en el Derecho comparado, Madrid, Civitas, pp. 135-206.

BARNETT, HILAIRE (2015): Constitutional \& Administrative Law, 11 ${ }^{\mathrm{a}}$ ed., London, Gavendish, 843 pp.

CHAPUS, RENÉ (2008), Droit du contentieux administratif, 13ª ed., Paris, Montchrestien, $1560 \mathrm{pp}$.

CHEVALLIER, J., (1970), L'élaboration historique du principe de séparation de la juridiction administrative et de l'administration active, prefacio de R. DRAGO, P., LGDJ, 317 pp.

CRAIG, Paul (2012), "La externalización de funciones públicas, la Ley británica de Derechos Humanos y el alcance del control judicial" (trad. esp. de O. BOUAZZA), en Revista Española de Derecho Administrativo, núm. 154, pp. 49-70. 
DARCY, GILLES \& PAILLET, M., (2000): Contentieux administratif, Paris, Dalloz, 318 pp.

DICEY, Albert V. (1915): Introduction to the study of the Law of the Constitution, 8 a ed., London, Macmillan, 435 pp.

DÍEZ DE VELASCO, M., (1986): "El Tribunal de Justicia de las Comunidades Europeas: sus fundamentos jurídicos y estructura”, en GARCÍA DE ENTERRÍA, E., GONZÁlEZ GAMPOS, J., \& MUÑOZ MACHADO, S., (directores), Tratado de Derecho Comunitario Europeo (Estudio sistemático desde el Derecho español), Madrid, Civitas, tomo I, pp. 629-653.

EVERLING, ULRICH (1993): "El Tribunal de Justicia de las Comunidades Europeas como tribunal administrativo”, en BARNÉS VÁZQUEZ, J. (coordinador), La justicia administrativa en el Derecho comparado, Madrid, Civitas, 1993, pp. 629-662.

FROMONT, M., (2008): "La justicie administrative en Europe: différences et convergentes", en Revue française de droit administratif, núm. 2, pp. 267-272.

GALERA RODRIGO, S., (2005): Sistema europeo de justicia administrativa, Madrid, Dykinson, 274 pp.

GARCÍA DE ENTERRÍA, E., (1986): "Las competencias y el funcionamiento del Tribunal de Justicia de las Comunidades Europeas. Estudio analítico de los recursos", en GARCÍA DE ENTERRÍA, E., GONZÁLEZ CAMPOS, J. \& MUÑOZ MACHADO, S., (directores), Tratado de Derecho Comunitario Europeo (Estudio sistemático desde el Derecho español), Madrid, Civitas, tomo I, pp. 655-729.

GARCÍA DE ENTERRÍA, E.,(1994): Revolución francesa y Administración contemporánea, $4^{\mathrm{a}}$ ed., Madrid, Civitas, 152 pp.

GARCÍA DE ENTERRÍA, E., (1998): "El fin del caso Factortame. La responsabilidad patrimonial final del Reino Unido", en Revista de Administración Pública, núm. 145, pp. 117-144.

GARCÍA DE ENTERRÍA, E., (2009), "La formación y el desarrollo en Europa de la Jurisdicción Contencioso-Administrativa. Su adquisición definitiva de un status de jurisdicción plena y efectiva", en Revista de Administración Pública, núm. 179, pp. 167-183.

GARCÍA LUENGO, J., (2004): El recurso comunitario de anulación: objeto y admisibilidad. Un estudio sobre el contencioso comunitario, Madrid, Thomson-Civitas, $341 \mathrm{pp}$.

GARCÍA URETA, A., (2016): "Los tribunales administrativos en el Reino Unido", en F. LÓPEZ R., (coord.), Las vías administrativas de recurso a debate, Madrid, INAP, pp. 149-181. 
GNEIST, RUDOLF VON (1875): Der Rechstaat, reimpresión, Kessinger. 2010, 206 pp.

GONZÁLEZ-VARAS, S., (1993): La Furisdicción Contencioso-Administrativa en Alemania, Madrid, Civitas, 485 pp.

HIMSWORTH, G.M.G. (1993): "Judicial review de los actos administrativos en el Reino Unido" y "La tutela cautelar en los procedimientos de judicial review en el Reino Unido", ambos en BARNÉS VÁZQUEZ, J., (coordinador), La justicia administrativa en el Derecho comparado, Madrid, Civitas, pp. 515-549.

HUERGO LORA, A., (2000): Las pretensiones de condena en el contencioso-administrativo, Pamplona, Aranzadi, 388 pp.

LAFERRIÈRE, J., (2007): "La jurisdicción administrativa en Francia”, en S. Rosado Pacheco (coord.), Modelos europeos de justicia contencioso-administrativa, Madrid, Dykinson, pp. 163-219.

LONG, M., WEIL, P., BRAIBANT, G., DELVOLVÉ, P. \& GENEVOIS, B. (2013): Les grands arrêts de la jurisprudence administrative, 19ª ed., Paris, Dalloz, 1054 pp.

LÓPEZ RAMÓN, F., (2007): "Las vías de consolidación de la planta orgánica del contencioso comunitario", en Revista de Derecho Comunitario Europeo, núm. 27, pp. 551-574.

LÓPEZ RAMÓN, F.,, coord. (2016): Las vías administrativas de recurso a debate, Actas del XI Congreso de la Asociación Española de Profesores de Derecho Administrativo (Zaragoza, 5-6 febrero 2016), Madrid, INAP, 838 pp.

MAYER, O., (1903): Le droit administratif allemand, edición francesa del autor, París, Giard et Brière, t. I.

MODERNE, F., (1993): "La justicia administrativa en Francia (II): proceso, técnicas de control, ejecución de sentencias", en J. BARNÉS VÁZQUEZ (coordinador), La justicia administrativa en el Derecho comparado, Madrid, Civitas, pp. 303-350.

NIETO, A., (1960): "Nueva ordenación de la Jurisdicción Contencioso-Administrativa en la República Federal de Alemania", en Revista de Administración Pública núm. 31, pp. 353-360.

OBSERVATOIRE DES MUTATIONS INSTITUTIONNELLES ET JURIDIQUES DE L'UNIVERSITÉ DE LIMOGES (2007): La justice administrative en Europe, Paris, PUF, 76 pp. (trad. inglesa en el mismo volumen, 76 pp.).

ORTEGA, M., (1999): El acceso de los particulares a la justicia comunitaria, Barcelona, Ariel, 251 pp. 
PACTEAU, B., PAULIAT, H., (2008): "Les convergentes européennes dans le déroulement du procès administratif", en Revue française de droit administratif, núm. 2, pp. 225-233.

PANGALLOZZI, M. C., (2016): "Le trasformazioni del diritto administrativo inglese: i 'nuovi' administrative tribunals", en Rivista Trimestrale di Diritto Pubblico, núm. 2, pp. 453-487.

RAMBAUD, P., (1993): "La justicia administrativa en Francia (I): introducción, organización, medidas cautelares", en BARNÉS VÁZQUEZ, J. (coordinador), La justicia administrativa en el Derecho comparado, Madrid, Civitas, pp. 277-301.

RASMUSSEN, H. (2000): "Remedying the crumbling EC judicial system”, en Common Market Law Review, vol. 37-5, pp. 1071-1112.

RODRÍGUEZ PONTÓN, F. J., (2005), La articulación de las garantías administrativas y jurisdiccionales en el sistema del Convenio Europeo de Derechos Humanos, Madrid, Thomson-Givitas, $210 \mathrm{pp}$.

SANTAMARÍA DACAL, A. I. (2001), "Defensa e ilustración de una Administración que se juzga a sí misma”, en Revista de Administración Pública, núm. 154, pp. 541-565.

SANTAMARÍA DACAL, A. I., (2002), "El Tribunal de Estrasburgo, el commissaire du gouvernement y la tiranía de las apariencias (Comentario a la sentencia Kress contre France)", en Revista de Administración Pública, núm. 157, pp. 305-319.

SAZ, SILVIA DEL (1992), "Desarrollo y crisis del Derecho Administrativo. Su reserva constitucional", en CHINCHILLA, C., LOZANO, B. y DEL SAZ, S., Nuevas perspectivas del Derecho Administrativo. Tres estudios, Madrid, Givitas, pp. 172-195.

SCHMIDT-ASSMANN, E., (2003): La teoría general del Derecho administrativo como sistema, trad. esp., Madrid, Pons, 475 pp.

SIERRA, S. DE LA (2002), "En busca del tiempo perdido. Breves apuntes sobre la reciente reforma de la justicia administrativa en Francia", en Civitas. Revista Española de Derecho Administrativo, núm. 116, pp. 557-576.

SOMMERMANN, K.-P. (1993): "La justicia administrativa en Alemania", en BARNÉS VÁZQUEZ, J., (coordinador), La justicia administrativa en el Derecho comparado, Madrid, Civitas, pp. 33-120.

TOCQUEVILLE, Al. de (1858): L'Ancien Régime et la Révolution, $4^{\mathrm{a}}$ ed., Paris, M. Lévy (trad. esp. de D. Sánchez de Aleu, Madrid, Alianza, 1982, 2 vols.). 
TORNOS MAS, J., (2016): "Los órganos administrativos independientes de resolución de recursos administrativos. La proportionate dispute resolution", en LÓPEZ RAMÓN, F., (coord.), Las vías administrativas de recurso a debate, Madrid, INAP, pp. 801-812.

UHLE, ARND \& LEHR, MARG (2007): "La protección jurídico-administrativa en la República Federal de Alemania”, en ROSADO PACHECO, S. (coord.), Modelos europeos de justicia contencioso-administrativa, Madrid, Dykinson, pp. 89-131.

VESTERDORF, BO (2003): "The Community court system ten years from now and beyond: challenges and possibilities", en European Law Review núm. 28, pp. 303-316.

WADE, WILLIAM \& FORSYTH, CHRISTOPHER (2014): Administrative Law, $11^{\text {a }}$ ed., Oxford University Press, 960 pp.

WEILER, JOSEPH H. H. (2002): "La arquitectura judicial después de Niza”, en GARCÍA DE ENTERRÍA, E. (director), La encrucijada constitucional de la Unión Europea, Madrid, Civitas, pp. 469-482. 